\title{
Article \\ Overflow Energy Loss Recovery System Based on Hydraulic Motor-Electric Generator
}

\author{
Zhongshen Li $\mathbb{D}$, Ling Su and Tianliang Lin* \\ College of Mechanical Engineering and Automation, Huaqiao University, Xiamen 361021, China; \\ lzscyw@hqu.edu.cn (Z.L.); 18014080019@stu.hqu.edu.cn (L.S.) \\ * Correspondence: 1t1@hqu.edu.cn
}

check for

updates

Citation: Li, Z.; Su, L.; Lin, T.

Overflow Energy Loss Recovery

System Based on Hydraulic

Motor-Electric Generator. Appl. Sci.

2021, 11, 941. https://doi.org/

10.3390/app11030941

Received: 28 December 2020

Accepted: 16 January 2021

Published: 21 January 2021

Publisher's Note: MDPI stays neutral with regard to jurisdictional clai$\mathrm{ms}$ in published maps and institutional affiliations.

Copyright: (C) 2021 by the authors. Licensee MDPI, Basel, Switzerland.

This article is an open access article distributed under the terms and conditions of the Creative Commons Attribution (CC BY) license (https:// creativecommons.org/licenses/by/ $4.0 /)$.

\begin{abstract}
Overflow loss is one of the main reasons for the inefficiency of the hydraulic system Aiming at the overflow loss in the hydraulic system, an energy recovery system based on a hydraulic motor and generator is proposed. Further, a pressure monitoring and control strategy based on variable speed control for electric generator is adopted, which can control the pressure differential between the inlet and outlet of the proportional relief valve as a small value, and achieve the purpose of energy recovery by reducing the loss of the pressure differential between the inlet and outlet of the relief valve. Through establishing a simulation system model and test platform, the stability, step response characteristics and energy saving of the system are studied. The results show that the energy recovery unit at the outlet of the relief valve does not affect the normal operation of the relief valve, but also greatly reduces the pressure regulation deviation. Besides, the efficiency of overflow loss recovery system about is $67 \%$.
\end{abstract}

Keywords: hydraulic transmission; energy saving; energy regeneration; overflow loss; electric generator

\section{Introduction}

Hydraulic transmission has low energy efficiency. Taking the hydraulic excavator as an example, its energy utilization rate is only about $20 \%$, and the efficiency of the hydraulic system is about 30\% [1]. Therefore, the research on energy saving technology of the hydraulic system is of great significance [2].

The energy consumption of a hydraulic system mainly includes throttling loss and overflow loss [3]. Between of them, the overflow loss is mainly caused by the relief valve, which is used to limit the maximum working pressure of the system or to achieve constant pressure control. In the traditional system, the outlet of relief valve is connected to the oil tank. Since the pressure of the oil tank is approximately zero, the pressure drop at the inlet and outlet of the relief valve is the inlet pressure of the relief valve, while the pressure at the oil inlet is the target adjustment pressure of the user, which is set by the user and cannot be changed. The higher the overflow pressure level is, the greater the pressure loss at the valve outlet [4]. With the increasing pressure level of hydraulic system, the problem of overflow loss will be more prominent.

At present, a lot of research has been carried out to reduce the overflow loss at home and abroad. However, most of these studies are from the overall system aspect, reducing the flow through the relief valve by the flow matching between the pump and the load, such as volume control technology [5-7], variable frequency technology [8,9], and so on. However, there is still overflow in this technology.

Aiming at the problem of overflow loss, Lin et al. proposed an energy regeneration system through an accumulator to recover the energy of overflow loss. The accumulator was connected to the outlet of the relief valve to reduce the pressure difference between the inlet and outlet of the relief valve, reduce the overflow loss, and recover the overflow energy to the accumulator $[10,11]$. However, in this method, the accumulator cannot be 
controlled actively. Although the energy can be recovered, the energy recovery rate is limited. Besides, the parameter matching requirements of the accumulator are complicated.

On the basis of the research of Lin et al., this paper further proposes an energy regeneration system through a hydraulic motor and electric generator for overflow loss. A lot of research has been conducted on the energy regeneration system and control methods [12,13]. At present, energy recovery technology is mostly for negative load conditions. According to the different energy storage, energy regeneration system can be divided into mechanical type, hydraulic type and electrical type. Among of them, mechanical type uses a flywheel, spring or seed as energy storage device [14-16]. However, recovery time of the mechanical type is short, and energy storage capacity is limited. The hydraulic regeneration system uses an accumulator as an energy storage device $[17,18]$. However, because the accumulator cannot be controlled actively, the corresponding control valve block is needed in the system. As a result, the overall energy recovery rate is limited and the control is complex.

The electric energy regeneration system is a combination of a hydraulic motor and generator. The generator is driven by a hydraulic motor to generate electricity. Wang et al. studied the electrical energy recovery for a negative load of construction machinery, including boom lowering and rotary braking. However, the system adopts volume control. Compared with the original valve control, its damping coefficient is reduced and the overall controllability is poor [19-22]. Moreover, the technology was aimed at the negative load condition and could not be directly applied to the overflow energy recovery system of the relief valve.

In this paper, in order to decrease the overflow pressure loss of the relief valve, by connecting the electrical energy recovery unit at the outlet of the pilot proportional relief valve, the pressure oil overflowing from the main valve port of the relief valve is recovered to the electric energy storage unit through the hydraulic motor and electric generator. A valve port pressure difference control strategy based on variable speed control is proposed to control the pressure drop of the proportional relief valve as a constant to improve the overflow energy recovery efficiency. The paper is organized as-2. Preliminary consideration. 3. Performance analysis. 4. Control strategy. 5. Simulation research. 6. Experimental research. 7. Conclusion.

\section{Preliminary Consideration}

\subsection{Traditional Relief Valve}

The structure of the traditional proportional relief valve is given in Figure 1. The basic function of the proportional relief valve is the same with that of the general pilot relief valve. The difference lies in the pilot valve- the pressure-regulating spring is replaced by the proportional electromagnet, which is a force-regulating proportional electromagnet. If a given current is preset in the electronic controller, there will be a positive proportional electromagnetic force acting on the pilot poppet valve 2. The larger the input current, the greater the electromagnetic force and the greater the regulating pressure.

The working process of the proportional relief valve is as follows. The pressure oil from the system (oil port P) acts on the main valve core 13. At the same time, the system pressure oil acts on the spring cavity of the main valve core through the damping $(10,11)$ and its pilot control circuit. By fixing the damping hole 10, the system pressure acts on the pilot cone valve core 2 , which is compared with the electromagnetic force of the push rod 6 . When the system pressure exceeds the set value of the corresponding electromagnetic force, the pilot valve core 2 opens and the pilot control oil flows back to the tank. Due to the role of the hydraulic resistance network in the control circuit, the pressure difference between the upper and lower ends of the main valve core 13 causes the main valve core 13 to lift up and open, and the valve port $P$ is connected with port $T$, and the oil at the main valve port flows back to the oil tank. In case of unexpected faults in the electrical or hydraulic system, such as excessive current input to electromagnet, resulting in peak pressure in the hydraulic system, a spring type pressure limiting valve 14 can be selected as the safety 
valve. The pilot type proportional relief valve has a remote-control port $K$. If the port $K$ is connected to another remote pressure regulating valve (the structure of the remote pressure regulating valve is the same as that of the pilot control part of the proportional relief valve), the hydraulic pressure at the upper end of the main valve core of the relief valve can be regulated by adjusting the spring force of the remote pressure regulating valve, so as to realize the remote control of the overflow pressure of the relief valve.

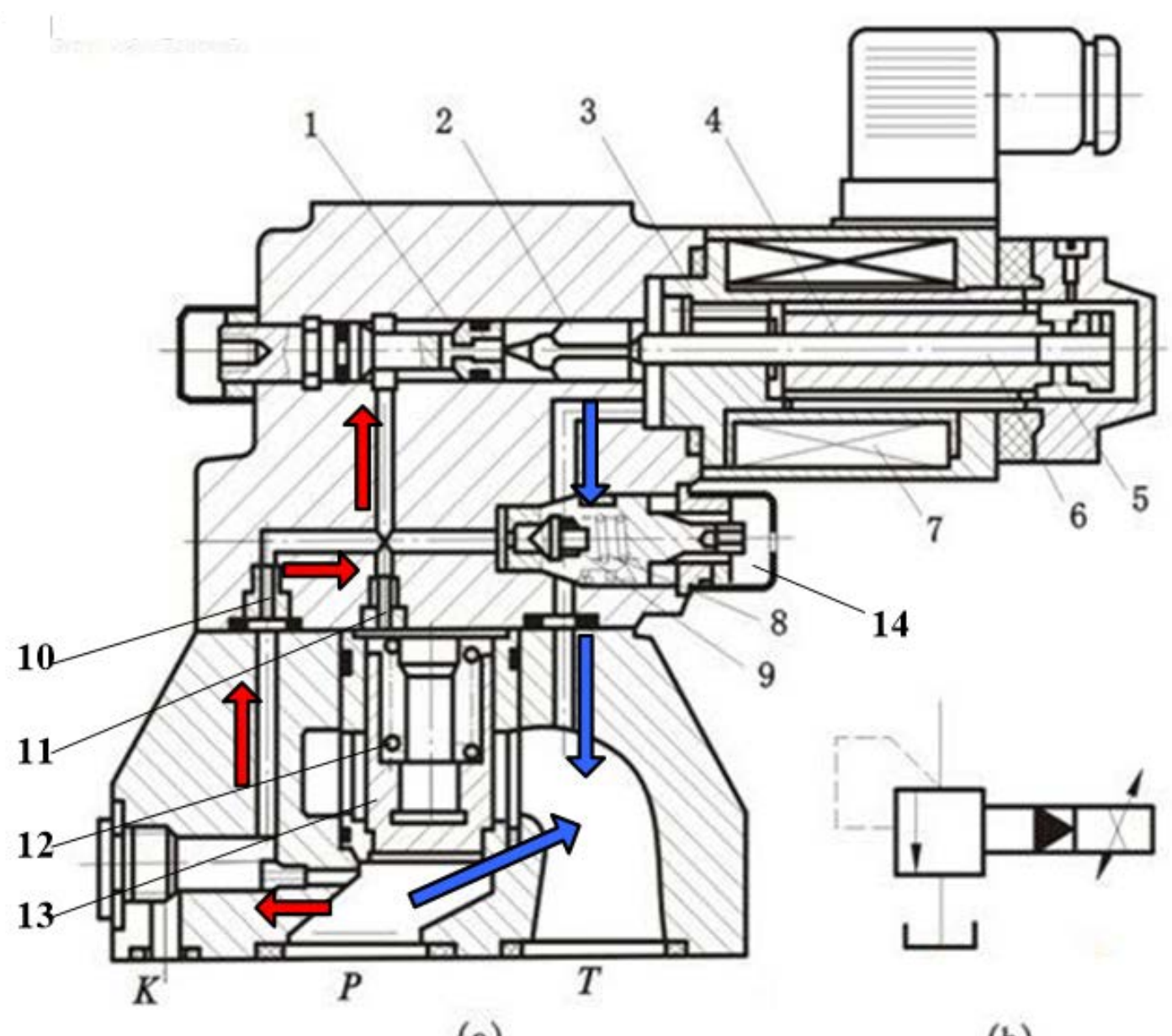

(a)

(b)

Figure 1. Structure diagram of traditional proportional relief valve. 1-pilot valve seat, 2-pilot poppet valve, 3-yoke; 4-armature, 5-spring; 6-push rod, 7-coil, 8-spring, 9-pilot valve, 10-fixed damping hole, 11-dynamic damping hole, 12-reset spring, 13-main valve core, 14-spring pressure limiting valve.

When the proportional relief valve works, the pressure oil of the pilot oil circuit and the main oil circuit return to the port $T$ together. In order to avoid the influence of the return oil back pressure on the pilot oil circuit, the pilot oil circuit can also be connected to the oil tank separately.

The working principle of the traditional proportional relief valve is given in Figure 2. The pressure difference loss at the relief valve port can be described as

$$
\Delta p=p_{1}-p_{2}
$$




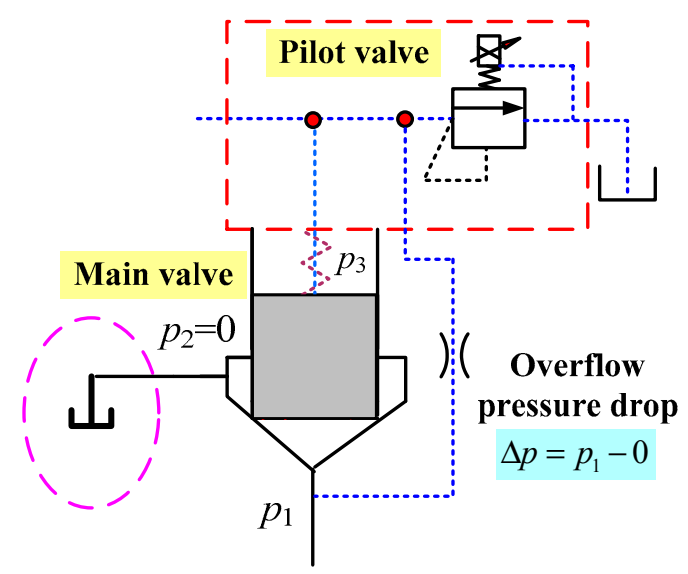

Figure 2. Working principle diagram of traditional proportional relief valve.

Because the main valve core outlet of the traditional proportional relief valve is connected to the oil tank. The tank pressure is basically $0 \mathrm{MPa}$. The pressure difference of the relief valve can be obtained as

$$
\Delta p_{\mathrm{T}}=p_{1}
$$

\subsection{Working Principle of Electric Energy Regeneration System for Relief Valve}

The electric energy recovery system of proportional relief valve is shown in Figure 3. Generally, the pilot oil outlet of traditional proportional relief valve and the oil outlet of main valve core return to the oil tank together. When the oil outlet of the main valve core of the proportional relief valve is connected with the energy recovery unit, there is a certain pressure in the energy recovery unit, which makes the oil outlet pressure rise. In order to avoid the influence of the energy recovery unit on the pilot pressure, the pilot oil circuit must be connected to the oil tank separately.

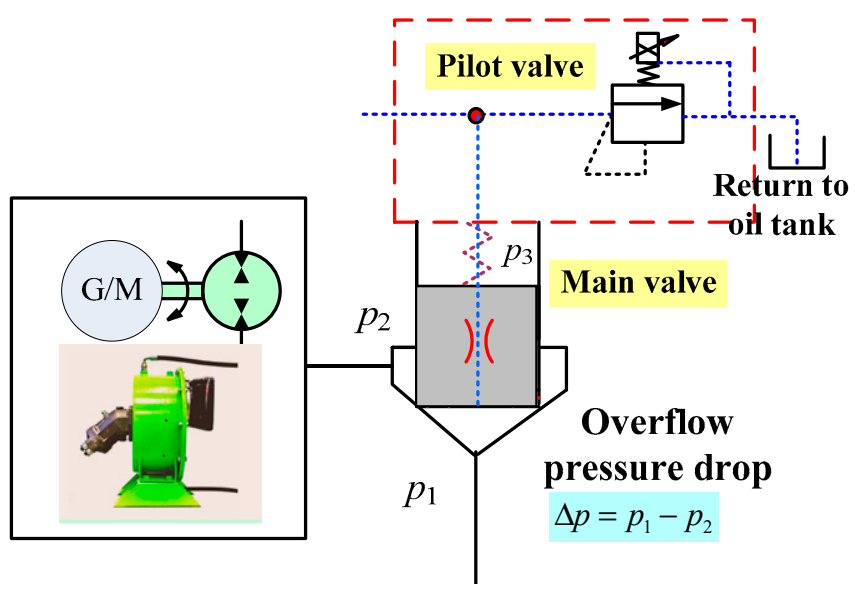

Figure 3. The schematic diagram of electric energy recovery system for proportional relief valve.

According to the schematic diagram shown in Figure 3, when the outlet pressure of the relief valve is higher, the differential pressure loss of relief valve is smaller. However, the excess energy generated by the pressure rise of the relief valve outlet can be recovered by energy regeneration system.

\section{Performance Analysis}

In order to study the electrical energy regeneration system of the relief valve, number analysis for relief valve is carried out to study the influence of back pressure on the relief valve. When establishing the mathematic model, the system is assumed that works in the ideal state, and 
(1) Only two hydraulic components (proportional overflow valve and back pressure valve) are considered. The system modeling is carried out by comparing the pilot stage and main stage of overflow valve;

(2) The system is free of leakage;

(3) The system oil tank pressure and return oil pressure are equal to zero;

(4) The density of oil is constant;

(5) The oil temperature and the volume modulus of elasticity of hydraulic oil are constant; and

(6) The influence of oil pipeline is ignored.

\subsection{Mathematical Model of Traditional Proportional Relief Valve}

For the convenience of analysis, the structure schematic diagram of traditional relief valve can be simplified as shown in Figure 4 .

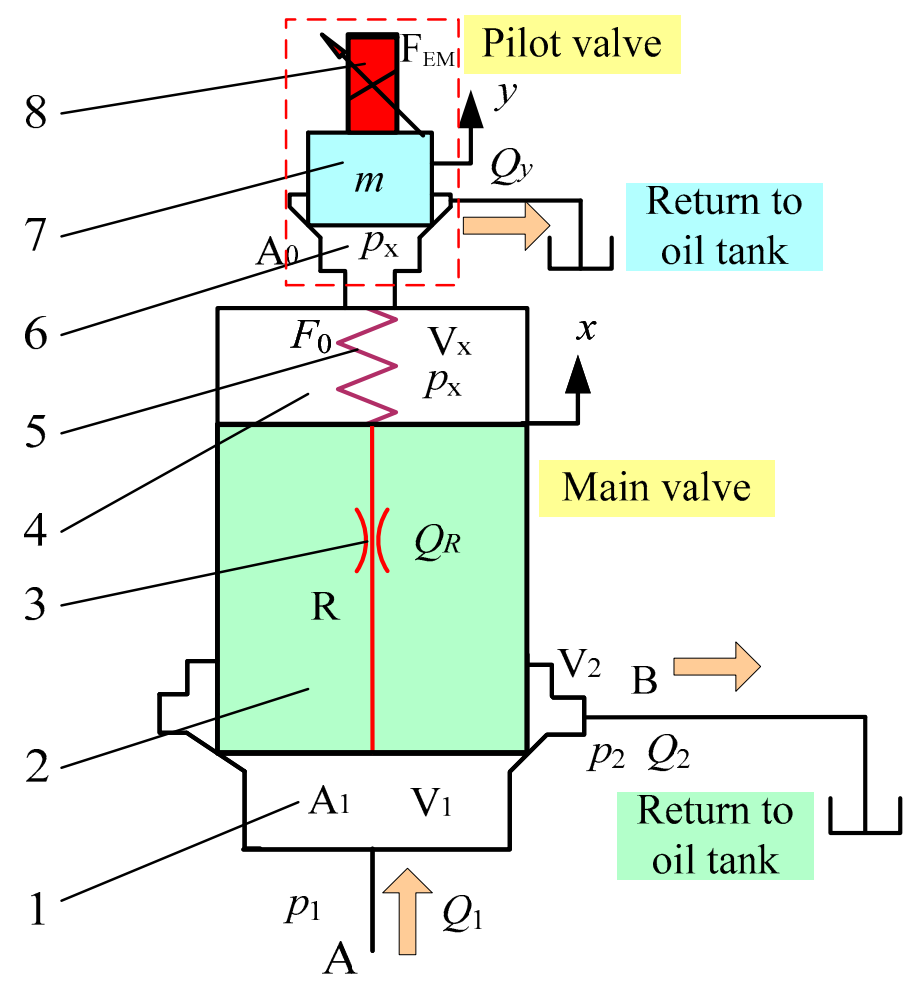

Figure 4. Simplified structure diagram of traditional proportional relief valve. 1 -front chamber of main valve core, 2-main valve core, 3-fixed damping, 4-spring cavity, 5-return spring, 6-front chamber of pilot valve core, 7-pilot valve core, 8-proportional electromagnet.

When the relief valve stops working, the main valve core and the pilot valve core are closed. The hydraulic oil from the pump reaches the front cavity 1 of the main valve core, enters the spring chamber 5 and the front chamber 6 of the pilot valve core through the pilot oil circuit and fixed damping hole R. when the hydraulic pressure acting on the pilot valve core is not enough to overcome the electromagnet output force, the pilot valve core 7 is closed, and the main valve core 2 is also closed. With the continuous oil supply of the hydraulic pump, the oil pressure rises. When the pilot valve core 7 is opened, the pilot oil will drain back to the oil tank separately. The oil in the pilot oil circuit flows, and the pressure drop in the spring chamber is less than the inlet pressure due to the pressure drop through the fixed damping hole $\mathrm{R}$. At this time, the resultant force on the main valve core is shown in Equation (3). The resultant force is greater than zero, and the main valve core is opened and the main valve port overflows.

$$
\sum F=p_{1} A_{1}-p_{x} A_{1}-F_{0}
$$


Dynamic force balance equation of pilot valve core can be described as

$$
\begin{gathered}
A_{0} p_{x}-F_{E M}-F_{f y}-F_{f a y}=m \frac{d y^{2}}{d t}+D_{y} \frac{d y}{d t}+K_{s y}\left(y_{0}+y\right) \\
F_{f y}=\pi \alpha_{D}^{2} y p_{x} d \sin 2 \beta_{1}
\end{gathered}
$$

Flow continuity equation of pilot valve port can be given as

$$
\begin{gathered}
Q_{y}-Q_{R}=A_{1} \frac{d x}{d t}+\frac{V_{x}}{E} \frac{d p_{x}}{d t} \\
Q_{y}=\alpha_{D} \pi d y \sin \beta \sqrt{\frac{2}{\rho} p_{x}} \\
Q_{R}=\alpha_{D} \frac{\pi d_{R}^{2}}{4} \sqrt{\frac{2}{\rho}\left(p_{1}-p_{x}\right)}
\end{gathered}
$$

Dynamic force balance equation of main valve core can be expressed as

$$
\begin{gathered}
A_{1} P_{1}-A_{1} P_{x}=M \frac{d x^{2}}{d t}+D_{x} \frac{d x}{d t}+K_{s x}\left(x_{0}+x\right)+F_{f x}+F_{f a x} \\
F_{f x}=\pi \alpha_{D}^{2} D x p_{1} \sin 2 \beta_{2}
\end{gathered}
$$

Flow continuity equation of main valve port can be given as

$$
\begin{gathered}
Q_{1}-Q_{R}-Q_{2}=A_{1} \frac{d x}{d t}+\frac{V_{1}}{E} \frac{d p_{1}}{d t} \\
Q_{2}=\alpha_{D} A(x) \sqrt{\frac{2}{\rho}\left(p_{1}-p_{2}\right)}
\end{gathered}
$$

The Laplace transformation is taken for Equations (4)-(12). The transfer function can be deduced as

$$
\begin{gathered}
\left(A_{0}-K_{f p}\right) P_{x}(s)-F_{E M}(s)=\left(m s^{2}+D_{y} s+K_{s y}+K_{f y}\right) Y(s) \\
K_{R} P_{1}(s)-K_{q y} Y(s)+A_{1} s X(s)=\left(-\frac{V_{x}}{E} s+K_{R} K_{q p}\right) P_{x}(s) \\
\left(A_{1}-K_{F p}\right) P_{1}(s)-A_{1} P_{x}(s)=\left(M s^{2}+D_{x} s+K_{s x}+K_{F x}\right) X(s) \\
Q_{1}(s)+K_{R} P_{x}(s)-\left(K_{Q x}+A_{1} s\right) X(s)=\left(K_{R}+K_{Q p}+\frac{V_{1}}{E} s\right) P_{1}(s)
\end{gathered}
$$

For the convenience of simplification, the sign definition can be given as

$$
\begin{gathered}
G_{1}(s)=\frac{1}{m s^{2}+D_{y} s+K_{s y}+K_{f y}} \\
G_{2}(s)=\frac{1}{-\frac{V_{x}}{E} s+K_{R} K_{q p}} \\
G_{3}(s)=\frac{1}{M s^{2}+D_{x} s+K_{s x}+K_{F x}} \\
G_{4}(s)=K_{Q x}+A_{1} s
\end{gathered}
$$




$$
\begin{gathered}
G_{5}(s)=\frac{1}{K_{R}+K_{Q p}+\frac{V_{1}}{E} s} \\
H_{1}(s)=A_{1}-K_{F p} \\
H_{2}(s)=A_{0}-K_{f p}
\end{gathered}
$$

In the steady-state working process of traditional proportional relief valve, the output force of electromagnet $F_{E M}(s)$ is the input signal, and the inlet pressure $P_{1}(s)$ is the output signal. The system is a constant flow system. The inlet flow $Q_{1}(s)$ is basically unchanged. The influence on the system is small. The interference term $Q_{1}(s)$ can be ignored. As shown in Figure 5, the block diagram of traditional proportional relief valve system can be obtained by combining each link of Equations (13)-(16).

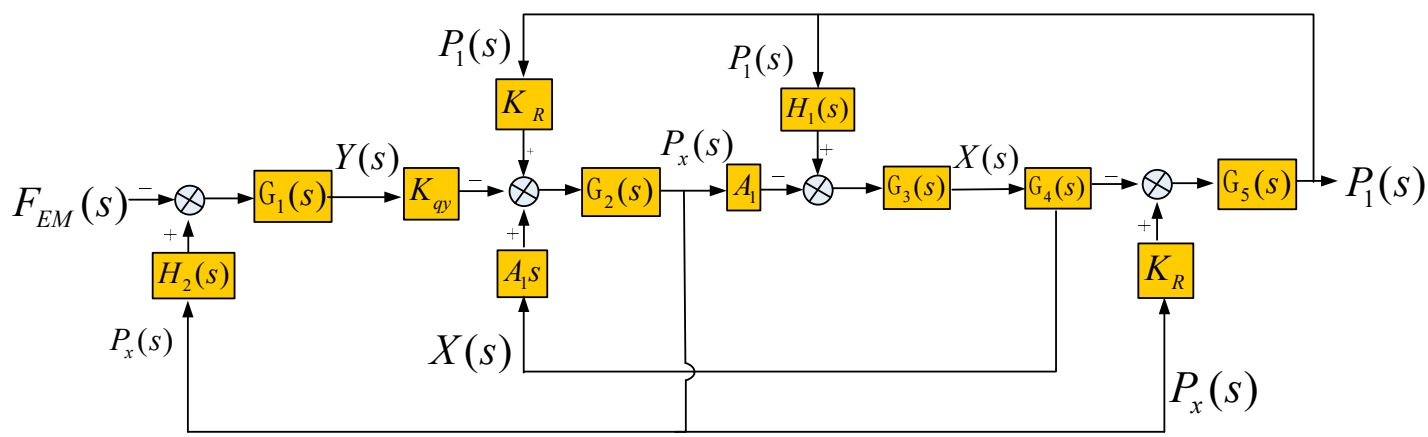

Figure 5. Block diagram of traditional proportional relief valve control system.

\subsection{Mathematical Model of Proportional Relief Valve with Energy Regeneration System}

As shown in Figure 6, the internal structure of the proportional relief valve with an energy recovery unit is shown. Compared with the traditional proportional relief valve, the outlet is connected with the energy recovery unit, and the outlet pressure is not equal to zero.

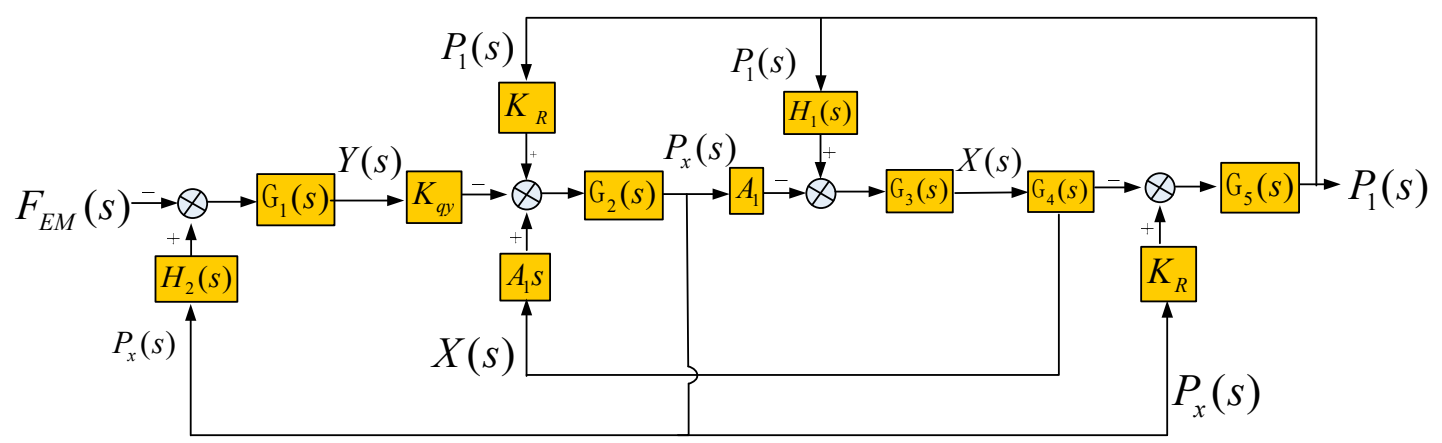

Figure 6. Structure diagram of proportional relief valve with energy regeneration system.

Dynamic force balance equation of main valve core can be expressed as

$$
\begin{gathered}
A_{1} P_{1}-A_{1} P_{x}=M \frac{d x^{2}}{d t}+D_{x} \frac{d x}{d t}+K_{s x}\left(x_{0}+x\right)+F_{f x}+F_{f a x} \\
F_{f x}=\pi \alpha_{D}^{2} D x\left(p_{1}-p_{2}\right) \sin 2 \beta
\end{gathered}
$$

Flow continuity equation of main valve port can be described as

$$
A_{1} P_{1}-A_{1} P_{x}=M \frac{d x^{2}}{d t}+D_{x} \frac{d x}{d t}+K_{s x}\left(x_{0}+x\right)+F_{f x}+F_{f a x}
$$




$$
F_{f x}=\pi \alpha_{D}^{2} D x\left(p_{1}-p_{2}\right) \sin 2 \beta
$$

The Laplace transformation is taken for Equations (24)-(27). The transfer function can be deduced as

$$
\begin{array}{r}
\left(A_{1}-K_{F p}\right) P_{1}(s)-A_{1} P_{x}(s)+K_{F p} P_{2}(s)=\left(M s^{2}+D_{x} s+K_{s x}+K_{F x}\right) X(s) \\
Q_{1}(s)+K_{R} P_{x}(s)+K_{Q p} P_{2}(s)-\left(K_{Q x}+A_{1} s\right) X(s)=\left(K_{R}+K_{Q p}+\frac{V_{1}}{E} s\right) P_{1}(s)
\end{array}
$$

In order to study the influence of outlet pressure $P_{2}(s)$ on the inlet pressure $P_{1}(s)$ of the relief valve in steady-state operation, the output force of electromagnet $F_{E M}(s)$ is the input signal. The inlet pressure $P_{1}(s)$ is the output signal. The outlet pressure $P_{2}(s)$ is the interference term. This paper mainly studies the influence of the outlet pressure $P_{2}(s)$ on the system stability, because the inlet flow $Q_{1}(s)$ is basically unchanged, the interference term $Q_{1}(s)$ may not be considered, and the system function block diagram is drawn, as shown in Figure 7.

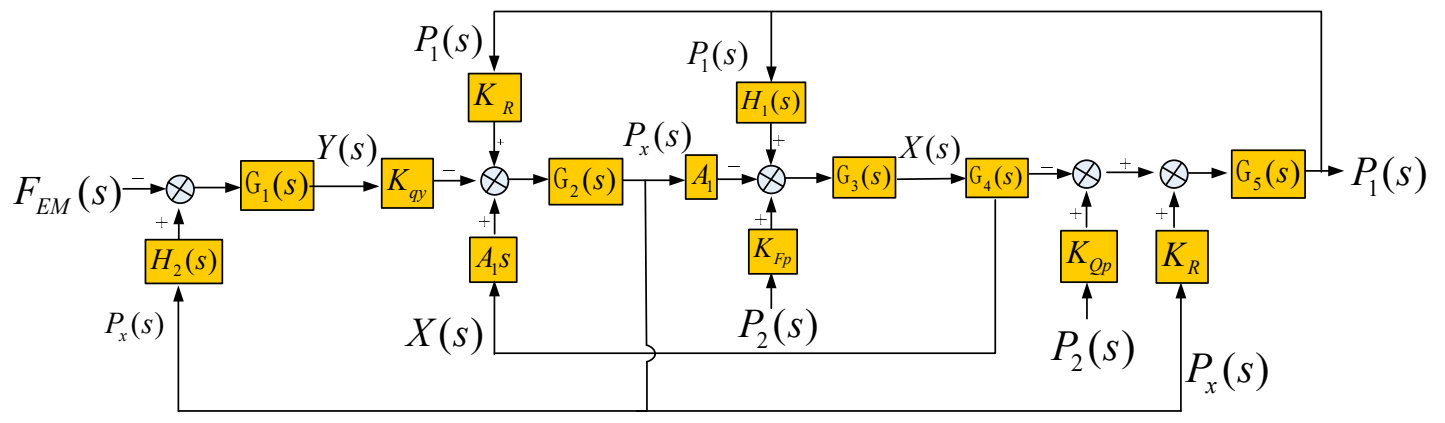

Figure 7. Block diagram of proportional relief valve control system with energy regeneration system.

It can be seen from Figure 7 that when the outlet pressure of proportional relief valve is taken as interference, it is very complex to simplify the transfer function of the control system block diagram. For the convenience of follow-up research, the block diagram is transformed into a signal flow diagram and simplified. Figure 8 shows the signal flow diagram after the conversion of Figure 7.

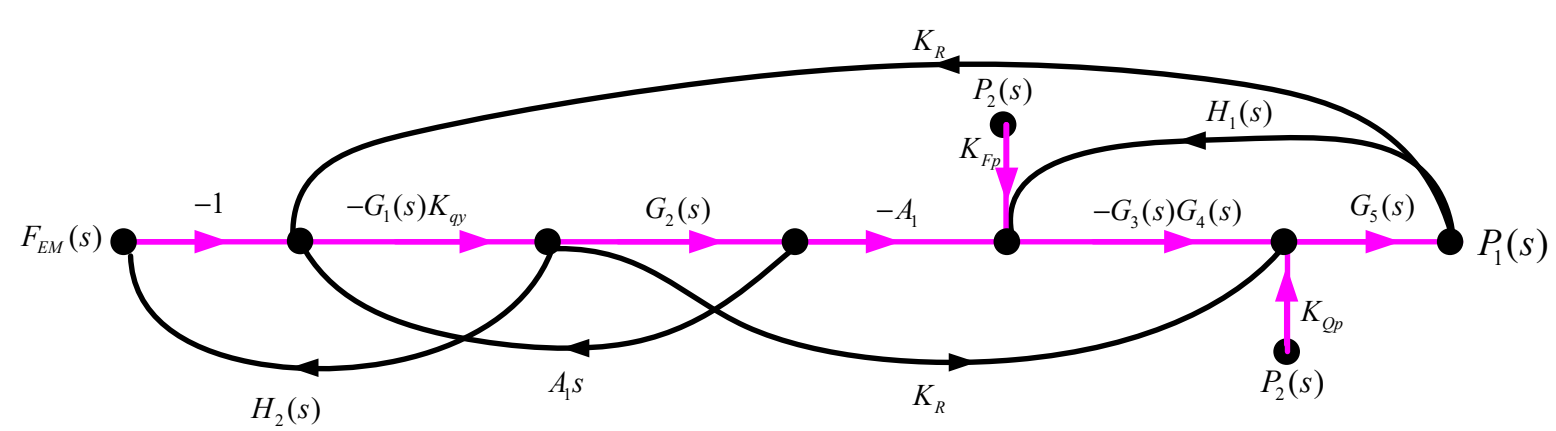

Figure 8. Signal flow diagram of proportional relief valve with the energy regeneration system.

Figure 9 shows the signal flow diagram after the conversion of Figure 5. It can be seen from Figures 8 and 9 that there are more back pressure interference items in the signal flow diagram of the traditional proportional relief valve after adding back pressure at the outlet of the proportional relief valve, and the other forward channels and feedback circuits are the same. 


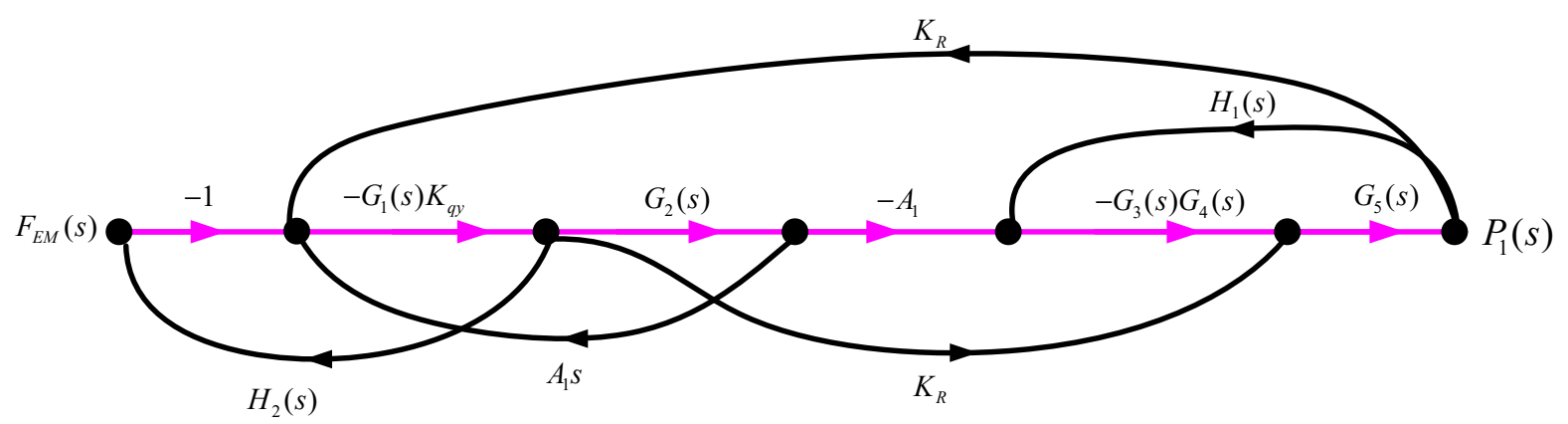

Figure 9. Signal flow diagram of the traditional proportional relief valve control system.

\subsection{Stability Analysis of Outlet Back Pressure System of Proportional Relief Valve}

The closed-loop transfer functions from input variables $F_{E M}(s)$ and disturbances $P_{2}(s)$ to output variables $P_{1}(s)$ can be obtained by the Mason formula [23]. The Mason formula can be expressed as

$$
M=\frac{1}{\Delta} \sum_{k=1}^{n} P_{k} \Delta_{k}
$$

According to Figure 9, the transfer function of the electromagnet output force $F_{E M}(s)$ of the traditional proportional relief valve to the inlet pressure can be deduced as

$$
\begin{aligned}
& \Delta=1+\mathrm{G}_{1}(s) \mathrm{G}_{2}(s) H_{2}(s) K_{q y}+\mathrm{G}_{2}(s) \mathrm{G}_{3}(s) A_{1}{ }^{2} s+\mathrm{G}_{3}(s) \mathrm{G}_{4}(s) \mathrm{G}_{5}(s) H_{1}(s) \\
& -\mathrm{G}_{2}(s) \mathrm{G}_{3}(s) \mathrm{G}_{4}(s) \mathrm{G}_{5}(s) A_{1} K_{R}-\mathrm{G}_{2}(s) \mathrm{G}_{5}(s) K_{R}{ }^{2} \\
& +\mathrm{G}_{1}(s) \mathrm{G}_{2}(s) \mathrm{G}_{3}(s) \mathrm{G}_{4}(s) \mathrm{G}_{5}(s) H_{1}(s) H_{2}(s) K_{q y} \\
& \sum_{k=1}^{n} P_{k} \Delta_{k}=\mathrm{G}_{1}(s) \mathrm{G}_{2}(s) \mathrm{G}_{3}(s) \mathrm{G}_{4}(s) \mathrm{G}_{5}(s) A_{1} K_{q y}+\mathrm{G}_{1}(s) \mathrm{G}_{2}(s) \mathrm{G}_{5}(s) K_{q y} K_{R} \\
& M_{1}(s)=\frac{\mathrm{P}_{1}(\mathrm{~s})}{\mathrm{F}_{E M}(\mathrm{~s})}=\frac{1}{\Delta_{1}} \sum_{k=1}^{n} P_{k} \Delta_{k}
\end{aligned}
$$

According to Figure 8, the interference $P_{2}(s)$ is input into the system from two different nodes. Therefore, the partial transfer functions $M_{2}(s)$ and $M_{3}(s)$ of the two-part transfer function $P_{2}(s)$ to the inlet pressure transfer function $P_{1}(s)$ can be obtained, respectively. The transfer function $M_{4}(s)$ of interference $P_{2}(s)$ to $P_{1}(s)$ is obtained by summation. By summing the transfer function $M_{4}(s)$ and $M_{1}(s)$, the total transfer function for the output inlet pressure $P_{1}(s)$ after adding the disturbance $P_{2}(s)$ can be obtained.

$P_{2}(s)$ as input, $M_{2}(s)$ can be described as

$$
\begin{gathered}
\sum_{k=1}^{n} P_{k} \Delta_{k}=-\mathrm{G}_{3}(s) \mathrm{G}_{4}(s) \mathrm{G}_{5}(s) K_{F P}\left[1+\mathrm{G}_{1}(s) \mathrm{G}_{2}(s) H_{2}(s) K_{q y}\right] \\
-\mathrm{G}_{2}(s) \mathrm{G}_{3}(s) \mathrm{G}_{5}(s) K_{F P} K_{R} A_{1} s \\
M_{2}(s)=\frac{\mathrm{P}_{1}(\mathrm{~s})}{P_{2}(\mathrm{~s})}=\frac{1}{\Delta} \sum_{k=1}^{n} P_{k} \Delta_{k}
\end{gathered}
$$

$P_{2}(s)$ as input, $M_{3}(s)$ can be described as

$$
\begin{gathered}
\sum_{k=1}^{n} P_{k} \Delta_{k}=K_{Q P} \mathrm{G}_{5}(s)\left[1+\mathrm{G}_{1}(s) \mathrm{G}_{2}(s) H_{2}(s) K_{q y}+\mathrm{G}_{2}(s) \mathrm{G}_{3}(s) A_{1}{ }^{2} s\right] \\
M_{3}(s)=\frac{\mathrm{P}_{1}(\mathrm{~s})}{P_{2}(\mathrm{~s})}=\frac{1}{\Delta} \sum_{k=1}^{n} P_{k} \Delta_{k}
\end{gathered}
$$


After adding back pressure interference input $P_{2}(s)$, the total transfer function $M_{5}(s)$ of inlet pressure $P_{1}(s)$ output can be given as

$$
\begin{gathered}
M_{4}(s)=M_{2}(s)+M_{3}(s) \\
M_{5}(s)=M_{1}(s)+M_{2}(s)+M_{3}(s)
\end{gathered}
$$

The closed-loop transfer function of the control system is obtained by introducing the actual values corresponding to the parameters in Equations (31)-(39), and the stability of the system is analyzed by the Routh criterion.

After numerical calculation, the closed-loop transfer function of traditional proportional relief valve system $M_{1}(s)$ and the closed-loop transfer function of system with back pressure disturbance at the outlet of proportional relief valve $M_{5}(s)$ are obtained

$$
\begin{gathered}
M_{1}(s)=2.46 \times 10^{11} \times \frac{s^{2}+6.52 \times 10^{4} s+6.66 \times 10^{8}}{s^{4}+3.95 \times 10^{4} s^{3}+4.04 \times 10^{7} s^{2}+6.26 \times 10^{11} s+3.85 \times 10^{14}} \\
M_{5}(s)=0.965 \times \frac{s^{4}+4.02 \times 10^{4} s^{3}+2.55 \times 10^{11} s^{2}+1.66 \times 10^{12} s+1.70 \times 10^{20}}{s^{4}+3.95 \times 10^{4} s^{3}+4.04 \times 10^{7} s^{2}+6.26 \times 10^{11} s+3.85 \times 10^{14}}
\end{gathered}
$$

The Routh array of the control system is as follows

$\begin{array}{cccc}s^{4} & 1 & 4.04 \times 10^{7} & 3.85 \times 10^{14} \\ s^{3} & 3.95 \times 10^{4} & 6.26 \times 10^{11} & \\ s^{2} & 2.45 \times 10^{7} & 3.85 \times 10^{14} & \\ s^{1} & 5.28 \times 10^{9} & & \\ s^{0} & 3.85 \times 10^{14} & & \end{array}$

It can be seen that

(1) The coefficients of the characteristic equation are not equal to zero;

(2) All the coefficient symbols of the characteristic equation are the same, and all the items in the first column of the Routh array are positive signs; and

(3) The proportional relief valve control system with back pressure interference is still stable, which lays a theoretical foundation for the follow-up research on energy recovery of overflow loss.

\section{Control Strategy}

The simplified working principle of the overflow energy regeneration system is given in Figure 10. In order to realize the recovery of overflow energy in the overflow process of the relief valve, the control flow chart of energy regeneration system for the relief valve is given in Figure 11.

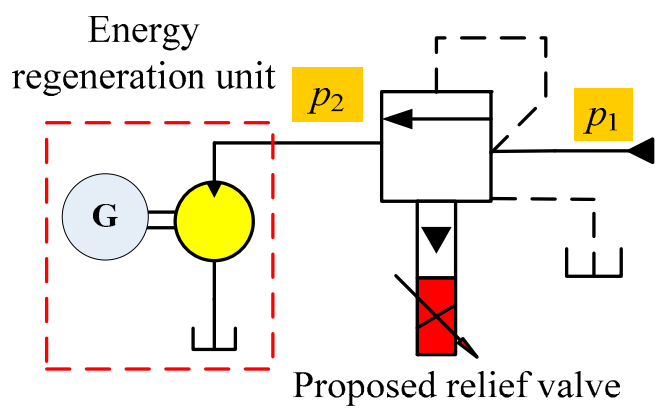

Figure 10. Simplified working principle diagram. 


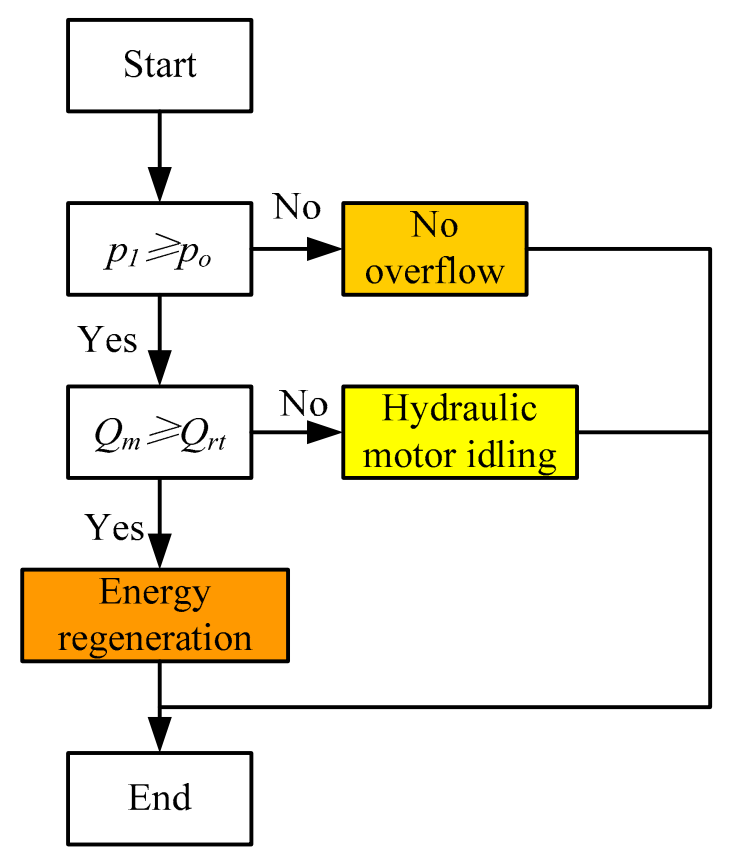

Figure 11. The control flow chart of energy regeneration system for the relief valve.

The pressure of inlet and outlet of relief valve can be detected through pressure sensors. Meanwhile, the flow rate through the hydraulic motor is indirectly detected by the electric generator.

The flow rate through the hydraulic motor can be described as

$$
Q_{m}=\frac{w D_{m}}{2 \pi \eta_{m}}
$$

During energy regeneration for the relief valve, the control framework can be given in Figure 12. The target pressure difference of the relief valve is taken as the input. The inlet and outlet pressure of the relief valve will be detected. Then, the pressure difference of the relief valve can be obtained as the feedback value of the energy recovery system. Through closed-loop feedback, PI control is used. On this basis, the differential pressure loss of the relief valve is reduced to realize the recovery of overflow energy.

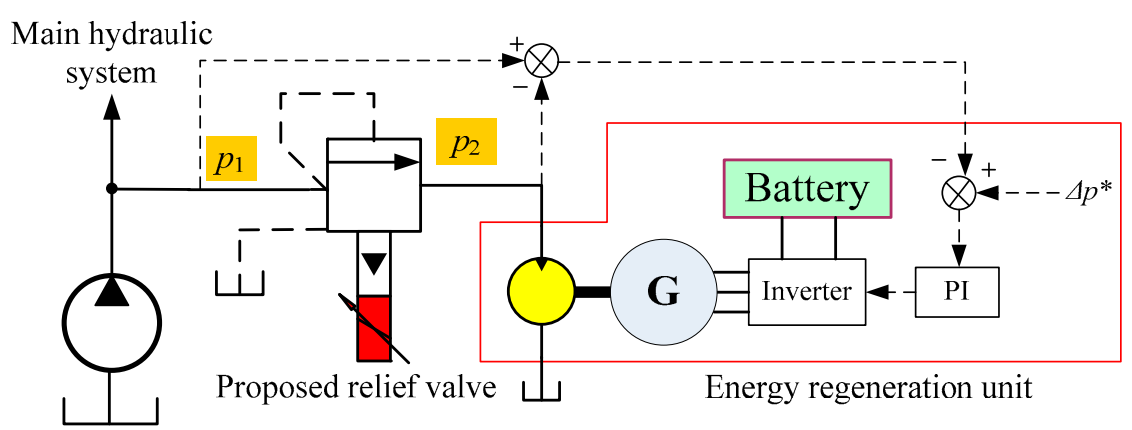

Figure 12. Control framework of energy regeneration system for the relief valve.

\section{Simulation Research}

To study the influence of the energy regeneration system on the relief valve, simulation research is carried out. The system schematic diagram is given in Figure 13. The system consists of a hydraulic pump source, safety valve, proportional relief valve and energy regeneration system. The safety valve is used to limit the maximum working pressure of the system. The electric energy regeneration system is composed of the hydraulic motor 
and electric generator. The 2-3 direction valve is used to realize the switching between traditional overflow and energy regeneration.

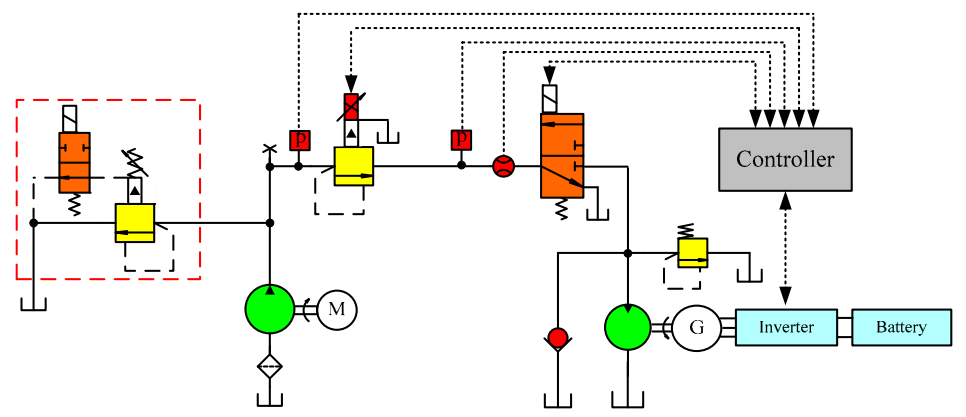

Figure 13. The system schematic diagram.

The simulation model based on AMESim is built and given in Figure 14. The parameters of the system are given in Table 1.

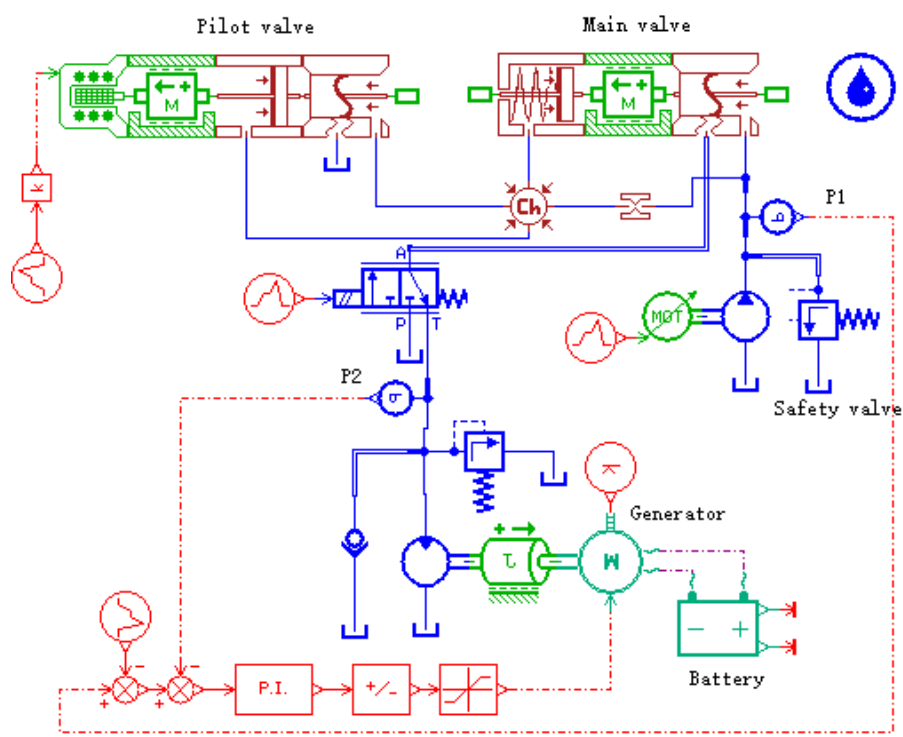

Figure 14. The simulation model.

Table 1. Parameters of components in the system.

\begin{tabular}{cc}
\hline Parameters & Value \\
\hline Displacement of pump & $50 \mathrm{~mL} / \mathrm{r}$ \\
Speed of electric motor & $0-2000 \mathrm{rpm}$ \\
Displacement of motor & $100 \mathrm{~m} / \mathrm{r}$ \\
Maximum torque of motor & $300 \mathrm{Nm}$ \\
Opening pressure of relief valve & $0.5 \mathrm{MPa}$ \\
Maximum displacement of main valve core & $4.6 \mathrm{~mm}$ \\
Main spool area & $226 \mathrm{~mm}{ }^{2}$ \\
Spring factor & $6 \mathrm{~N} / \mathrm{mm}^{-}$ \\
Flow coefficient & 0.7 \\
Maximum flow & $100 \mathrm{~L} / \mathrm{min}$ \\
\hline
\end{tabular}

The feasibility of system differential pressure control is given in Figure 15. 


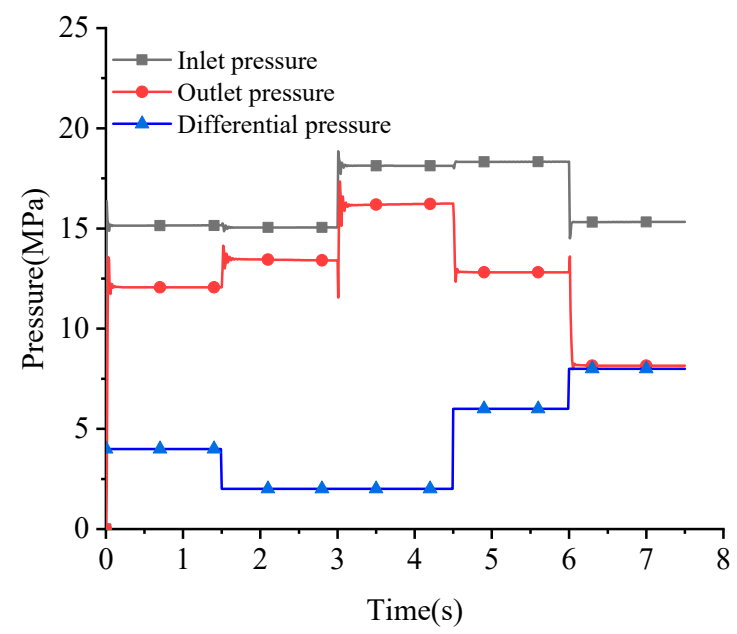

Figure 15. Pressure difference control simulation curve.

At the beginning, the set pressure of the proportional relief valve is $15 \mathrm{MPa}$. At $3 \mathrm{~s}$, the set pressure of this relief valve is adjusted to $18 \mathrm{MPa}$, and at $6 \mathrm{~s}$, the set pressure of the relief valve is set to $15 \mathrm{MPa}$. By controlling the electric generator torque, the inlet pressure of the hydraulic motor can be controlled. At the beginning, the inlet pressure of the hydraulic motor is $12 \mathrm{MPa}$, and at $1.5,3,4.5 \mathrm{~s}$, the inlet pressure of the hydraulic motor is adjusted 13,16,12, and $8 \mathrm{MPa}$, respectively. As can be seen, the pressure differences of the relief valve can be controlled through the energy regeneration system.

In order to study the control characteristics of the system, the pressure response of the system is simulated.

Under the condition of the overflow pressure of the proportional relief valve of $20 \mathrm{MPa}$ and the flow of $100 \mathrm{~L} / \mathrm{min}$, the constant pressure control simulation of the outlet pressure is carried out. The pressure step response curve is given in Figure 16. As can be seen, for different target pressures of the relief valve outlet, the actual pressure can be realized within $80 \mathrm{~ms}$.

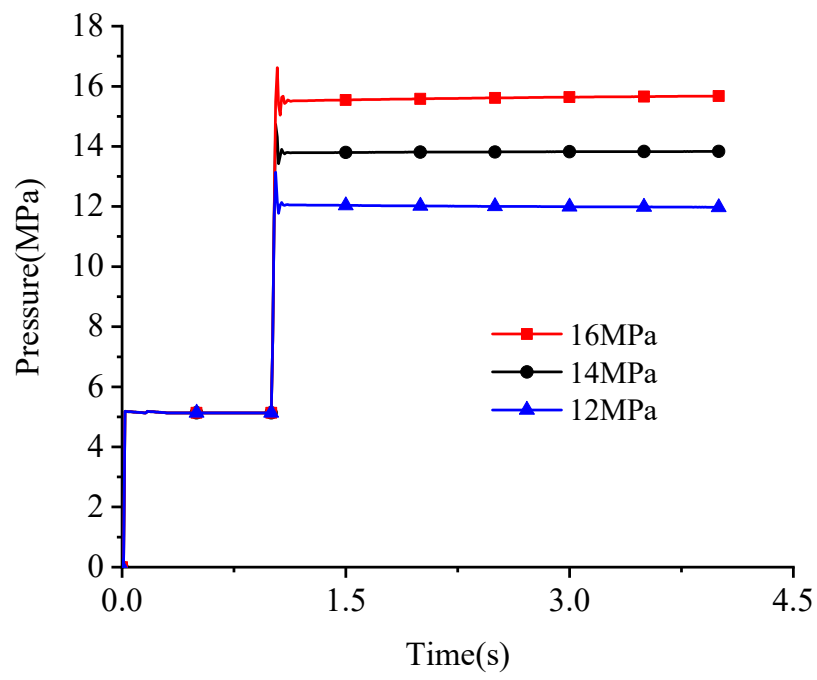

Figure 16. The pressure step response curve.

To analyze the influence of system flow rate on system pressure control, the influence of system flow change on pressure is simulated.

The pressure change curve when the flow rate changes is given in Figure 17. As can be seen, when the flow rate changes through the proportional relief valve, the inlet pressure and outlet pressure of the relief valve fluctuate slightly, but maintain stability quickly. The change curve of spool displacement, hydraulic motor speed and torque 
when the flow rate changes is given in Figure 18. As can be found, when the flow rate changes, the hydraulic motor speed also changes correspondingly to adapt to the change of flow rate. Since the target pressure does not change, the torque of the hydraulic motor remains unchanged.

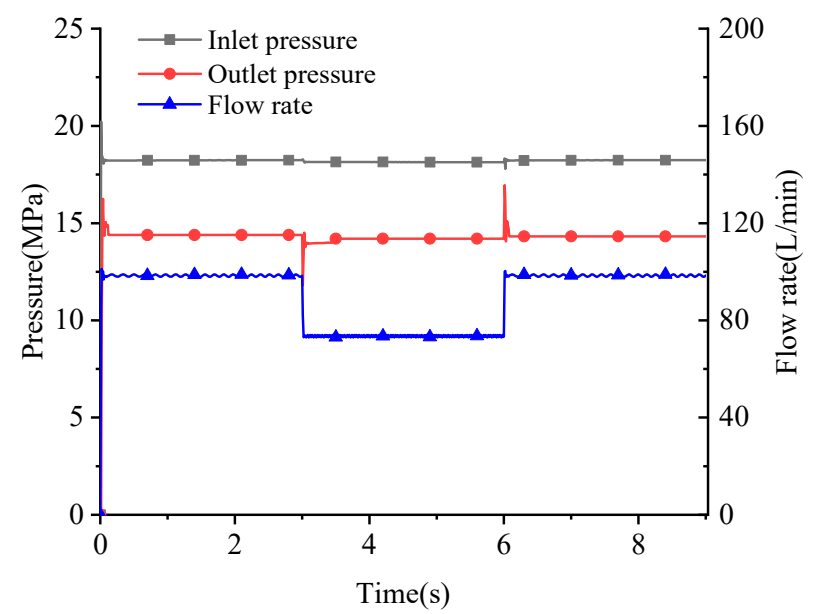

Figure 17. Pressure varies curve with flow change.

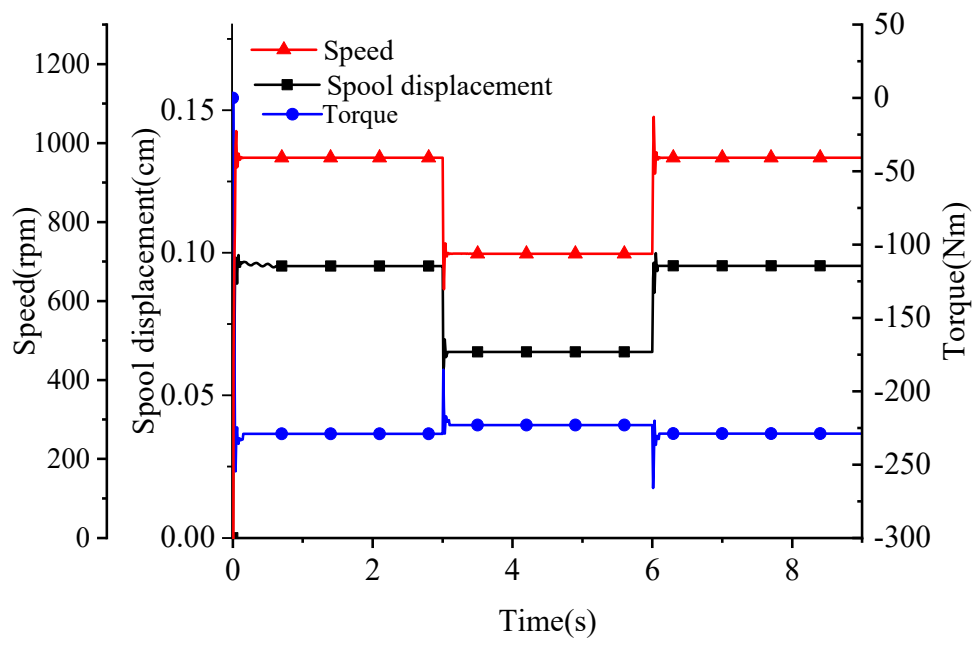

Figure 18. Spool displacement, speed and torque curve under flow variation.

Pressure, flow rate and main spool displacement curves of relief valve under traditional working mode and with energy regeneration are given in Figure 19. The outlet pressure of the proportional relief valve is $0 \mathrm{MPa}$ from $0-0.5 \mathrm{~s}$, and the relief valve works in the traditional overflow mode. At $0.5 \mathrm{~s}$, the system performs energy recovery, and the outlet pressure of the relief valve is $15 \mathrm{MPa}$. At this time, the displacement of the main valve core increased immediately, from 0.04 to $0.072 \mathrm{~cm}$; the pressure at the inlet of the overflow valve decreased from 22-21.5 MPa, while the system flow remained unchanged. Compared with the traditional working mode, the flow fluctuation of the system decreased and became more stable. This shows that the inlet pressure can be reduced and the pressure regulating deviation of the overflow valve can be reduced to a certain extent when the energy recovery unit is added. 


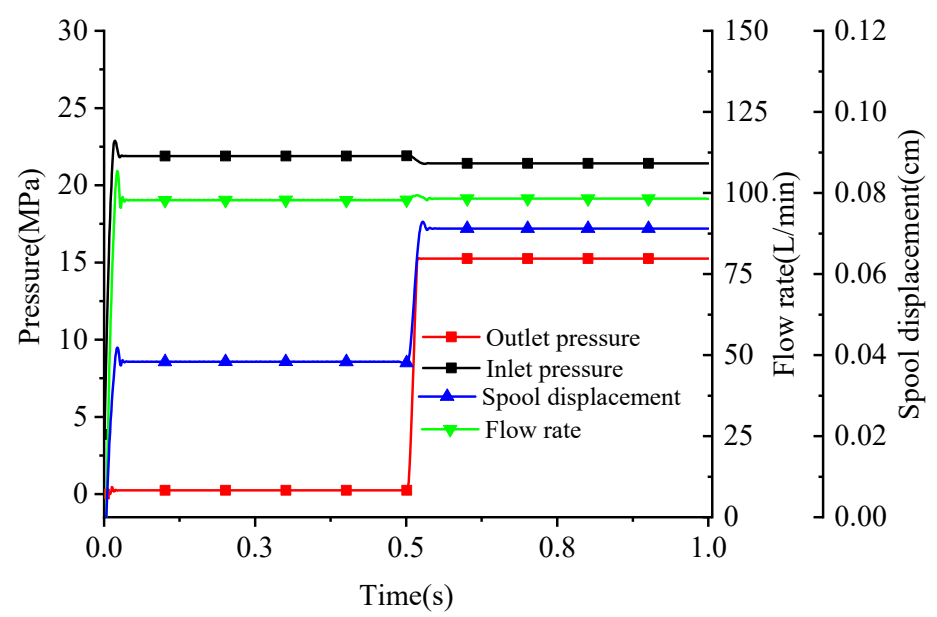

Figure 19. Pressure, flow rate and main spool displacement curves of relief valve under traditional working mode and with energy regeneration.

In order to further analyze the influence of the pressure regulating deviation of the relief valve in the energy regeneration system, the static characteristics of the relief valve are tested under different outlet pressures. The overflow pressure of the proportional relief valve is set as $21 \mathrm{MPa}$. The change of the inlet pressure of the relief valve is observed by increasing the system flow. The pressure regulation deviation characteristic curve is given in Figure 20 when the outlet pressure is 0,15 and $18 \mathrm{MPa}$. The simulation results show that-with the increase of the outlet pressure, the pressure regulating deviation of the relief valve gradually decreases. Therefore, the pressure regulating deviation of the relief valve can be reduced and the pressure control precision of the relief valve can be improved by connecting the energy recovery unit at the outlet of the relief valve.

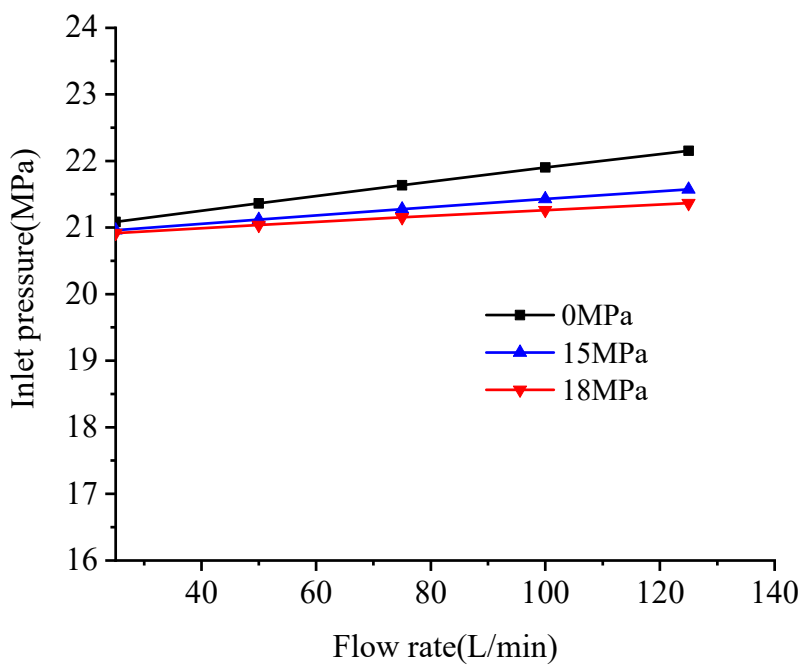

Figure 20. Pressure regulation characteristic curve under different back pressures.

\section{Experimental Research}

Further experimental research is carried out as well. The schematic diagram of the test platform is given as Figure 13. The whole energy regeneration system is based on LabVIEW for control and data acquisition. Part of the experimental system is shown in Figure 21. 


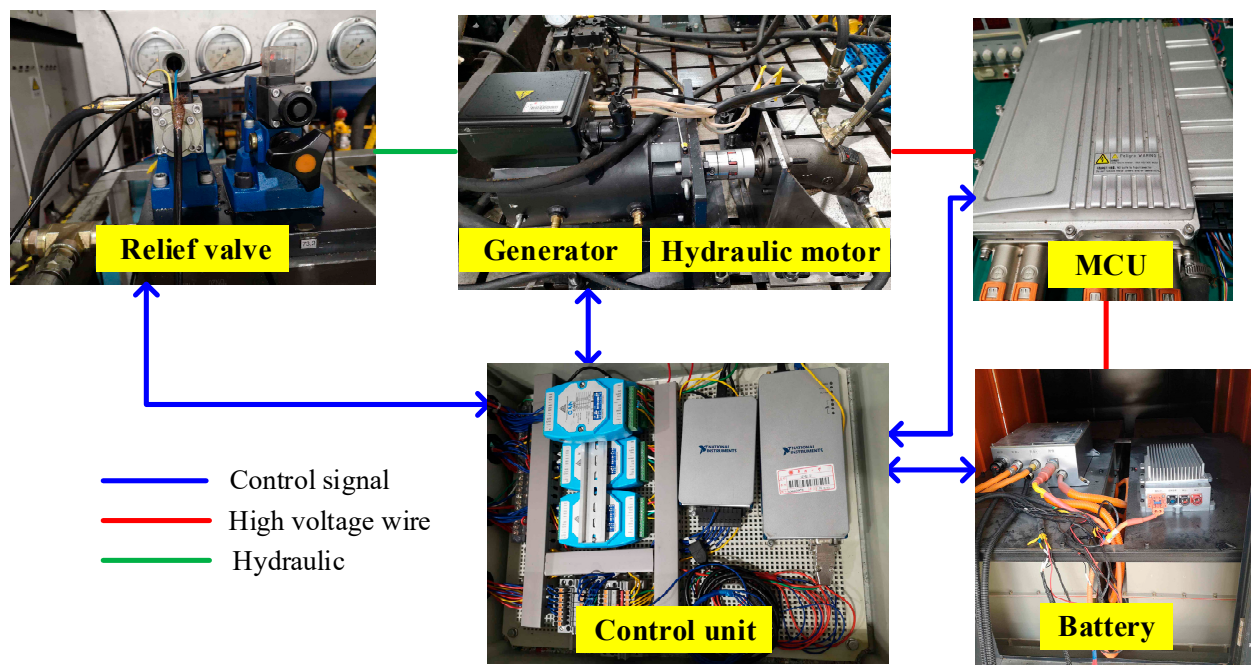

Figure 21. Overflow loss energy regeneration test platform.

\subsection{Control Characteristics}

In the differential pressure control test of energy regeneration system, the change of outlet pressure is observed by changing the pressure at the inlet of the proportional relief valve. The test results are shown in Figure 22. It can be seen that the outlet pressure changes with the inlet pressure, so that the valve port pressure difference is maintained at the target value. The experimental results are consistent with the simulation.

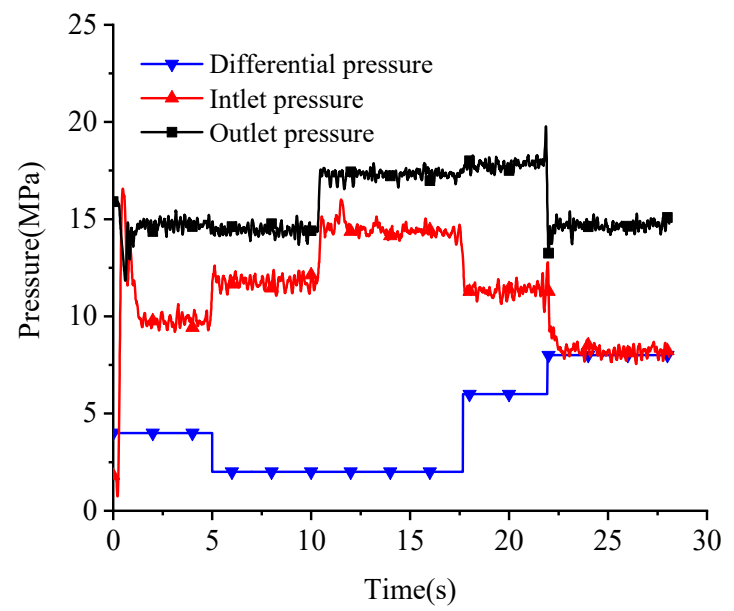

Figure 22. Differential pressure control curve.

The response curve of the control outlet pressure step change is given in Figure 23. When the target pressure step changes, the actual pressure can quickly follow the response. The response of outlet pressure under different pressure differences when the step change of the inlet pressure is controlled, which is given in Figure 24. Under different pressure difference, outlet pressure can respond quickly. 


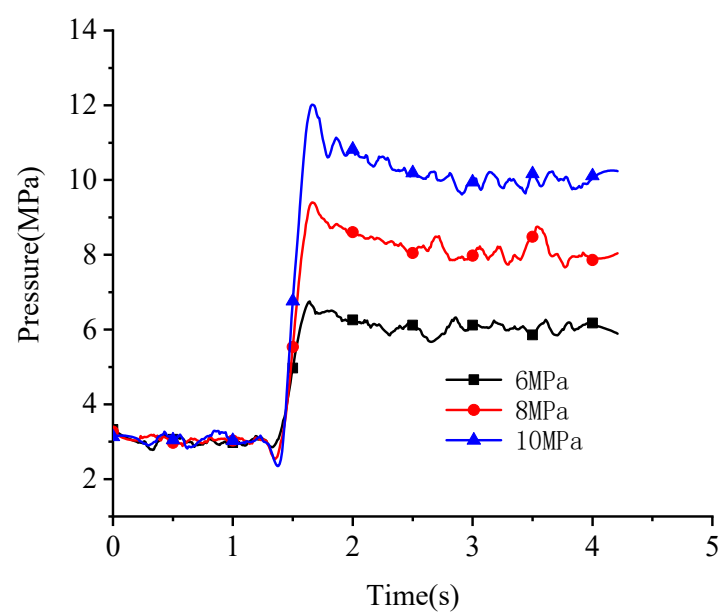

Figure 23. Step change curve of the outlet pressure.

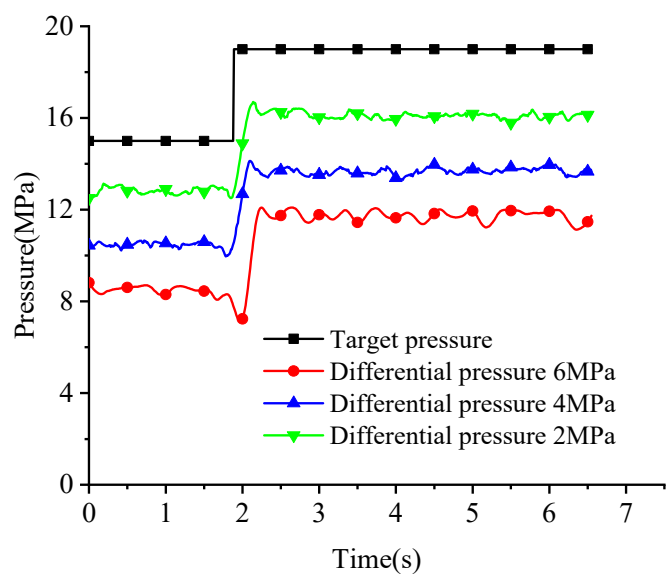

Figure 24. Variation curve of the outlet pressure under different pressure differences.

The pressure curve when the system flow changes is given in Figure 25. The inlet target pressure of the relief valve is $18.5 \mathrm{MPa}$, and the pressure difference of valve port is $4 \mathrm{MPa}$. When the flow rate changes, due to the influence of the pressure regulating characteristics of the relief valve, the inlet pressure of the relief valve slightly decreases, but it is basically not affected by the flow rate change.

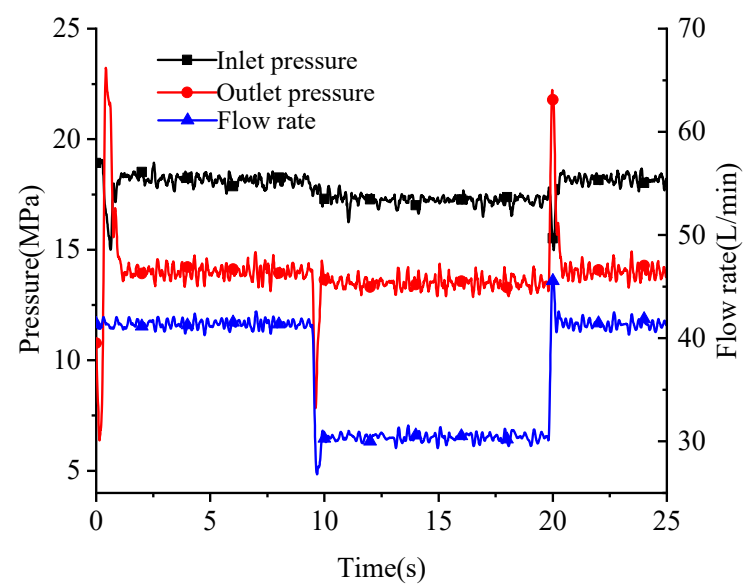

Figure 25. Pressure change curve with flow change.

The pressure control of relief valve is tested under different outlet pressures, and the results are shown in Figure 26. When the outlet pressure of the relief valve is $0 \mathrm{MPa}$, 
the pressure regulating deviation of the relief valve is $10 \%$. When the outlet pressure is 15 and $18 \mathrm{MPa}$, the pressure regulating deviation is $5 \%$ and $2.8 \%$, respectively. The larger the outlet pressure is, the smaller the pressure regulation deviation of the relief valve is. Therefore, the energy recovery of the relief valve can improve the pressure control characteristics of the relief valve.

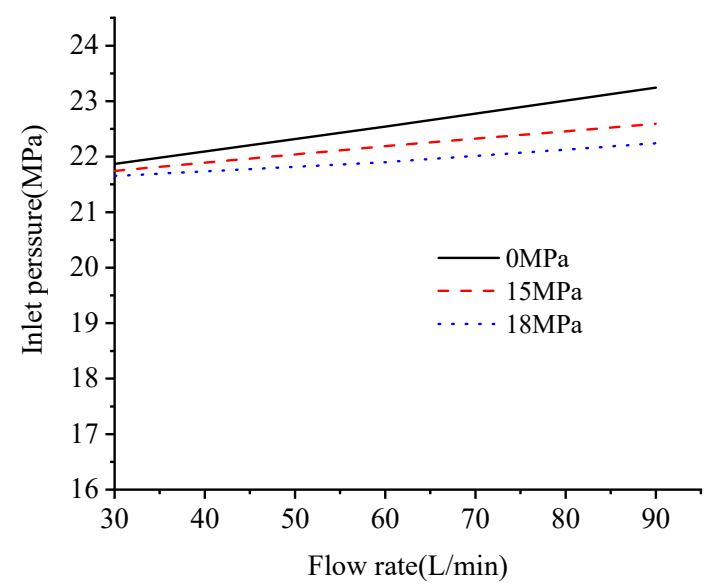

Figure 26. Pressure regulating deviation test curve of the relief valve.

\subsection{Energy Saving Characteristics}

The efficiency of the relief valve regeneration system can be described as

$$
\eta=\frac{W_{2}}{W_{1}} \times 100 \%
$$

The input energy of the relief valve can be given as

$$
W_{1}=p q t
$$

The regenerated energy of battery can be described as

$$
W_{2}=-\int_{0}^{t} U I d t
$$

The input pressure and flow of relief valve under different pressure difference control are shown in the Figures 27 and 28.

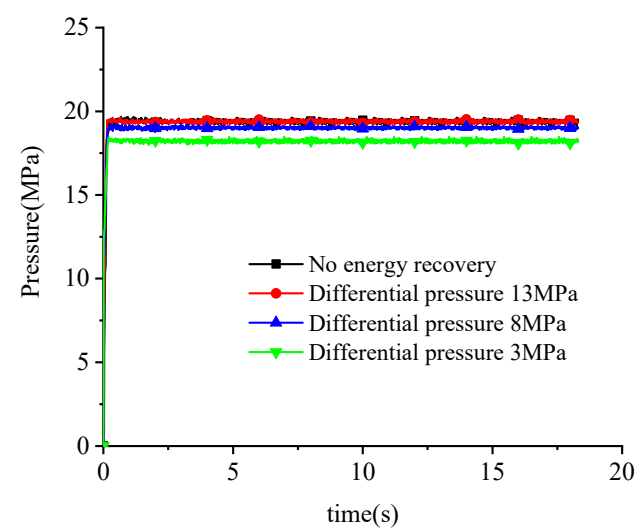

Figure 27. The input pressure of the relief valve under different pressure difference control. 


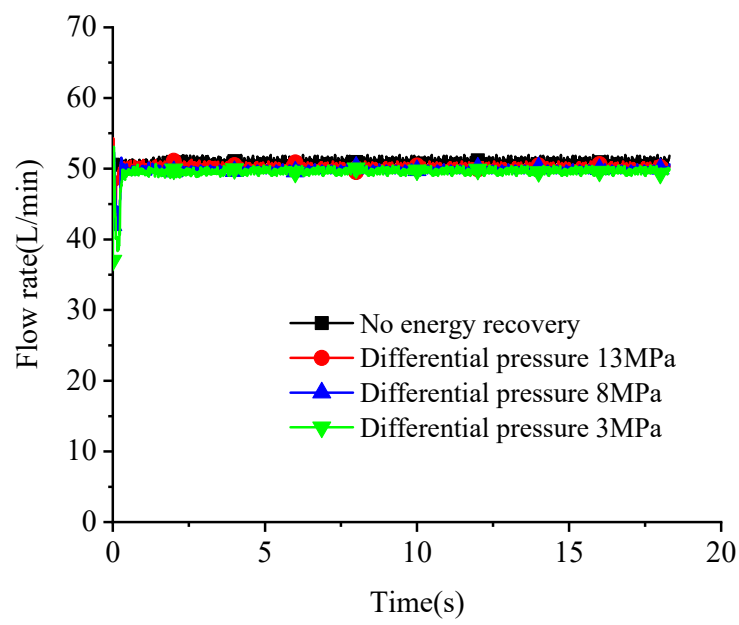

Figure 28. The input flow of the relief valve under different pressure difference control.

As can be seen from Figures 27 and 28, the smaller the pressure difference, the smaller the energy consumption. Therefore, during the energy recovery of overflow loss, the pressure difference of relief valve port can be kept at the minimum value to ensure the operation of the relief valve through the control of valve port pressure difference, which can improve the energy saving of the system.

\subsection{Energy Regeneration System Application in Throttle-Governing System}

In order to analyze the practical engineering application of the overflow energy recovery system more effectively, the throttle-governing system with overflow energy regeneration system experimental platform is built and given in Figure 29. The partial physical diagram of the experimental system is given in Figure 30.

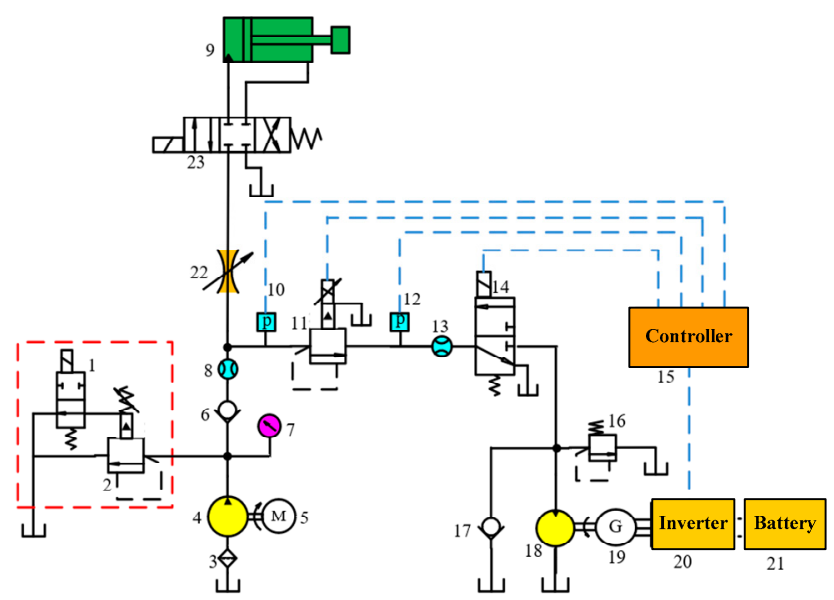

Figure 29. Throttle-governing system with overflow energy regeneration system. 


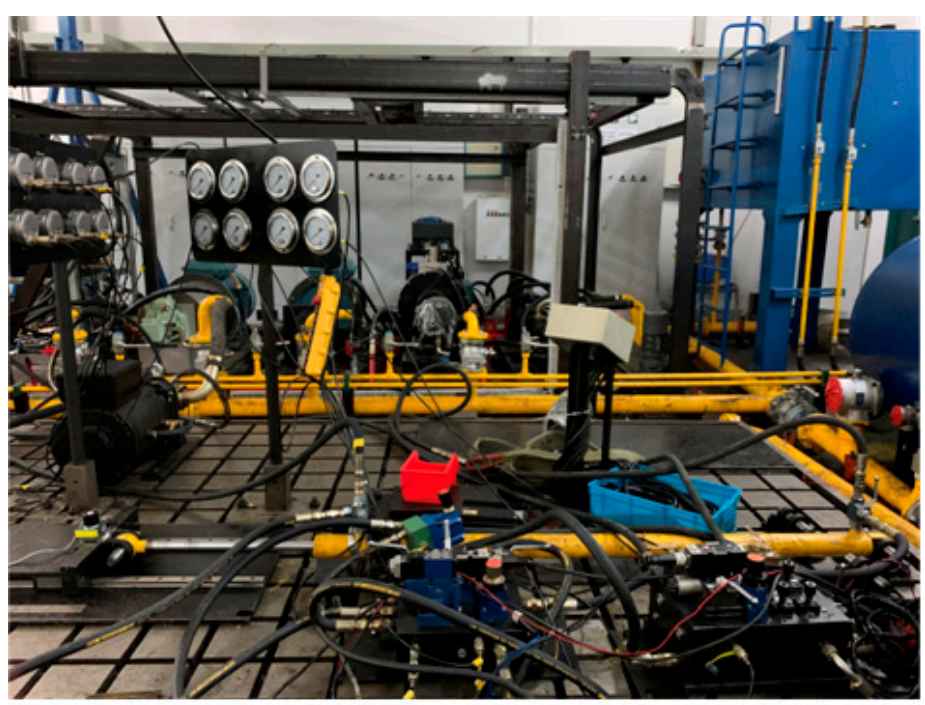

(a) Throttle govening system

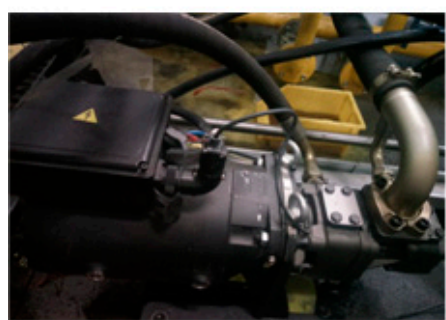

(b) Energy

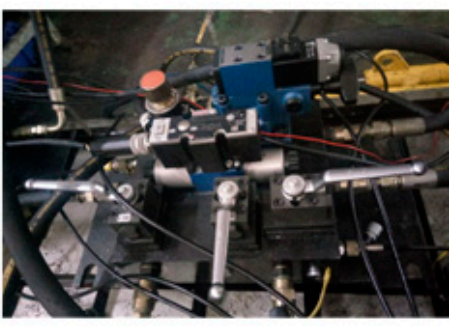

(c) Control valve

regeneration system

Figure 30. Partial physical diagram of the experimental platform.

For convenient comparison, the throttle-governing system without an overflow energy regeneration system is also implemented. The same control inputs are applied to these two systems. The displacement of the cylinder in these two systems is given in Figure 31. The inlet pressure of the relief valve is given in Figure 32. The overflow oil is given in Figure 33. As can be seen, the control performance of the cylinder and the relief valve are close.

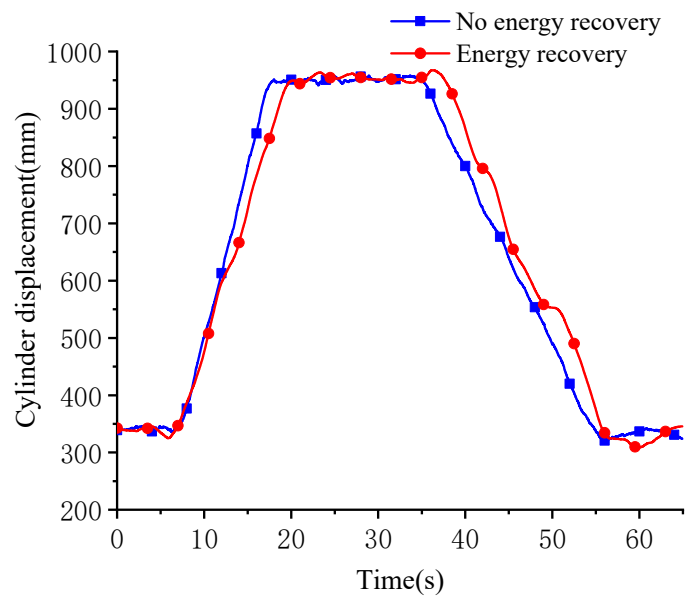

Figure 31. Displacement of the cylinder in these two systems. 


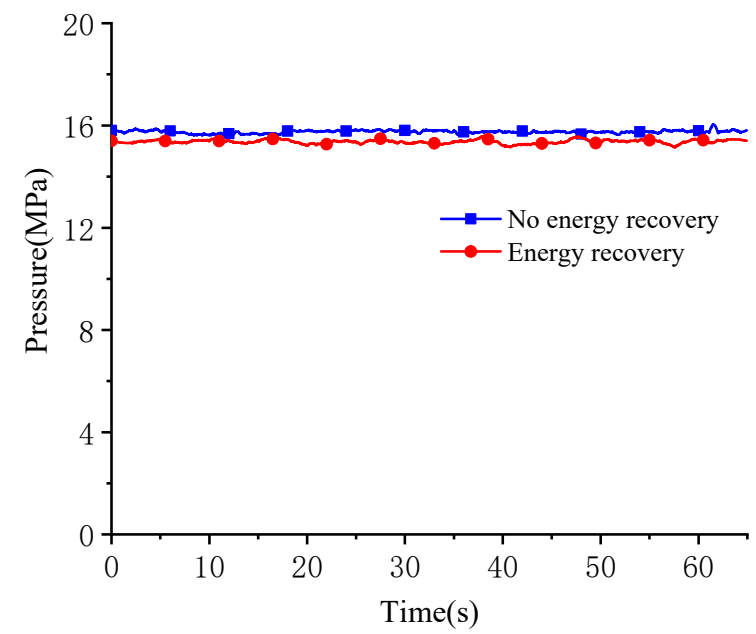

Figure 32. Inlet pressure of the relief valve.

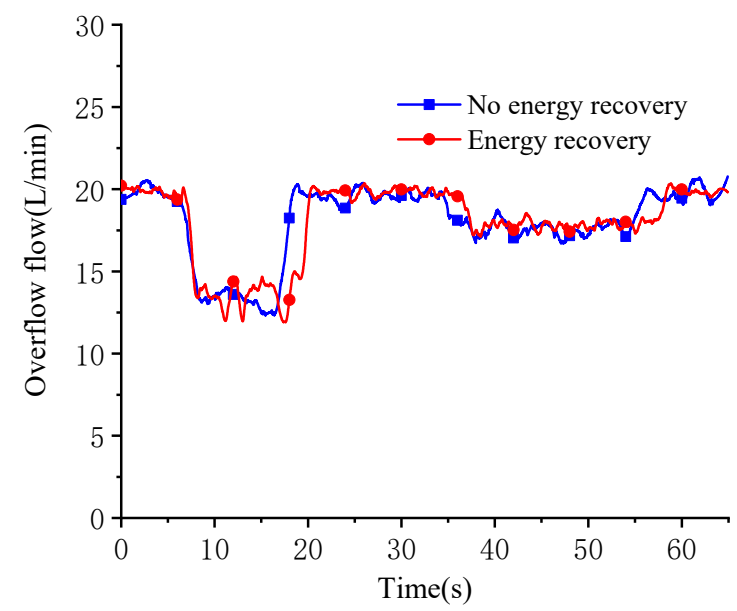

Figure 33. Overflow oil.

The power consumed in throttle-governing system without the energy regeneration system is given in Figure 34. The power consumed in the throttle-governing system with the energy regeneration system is given in Figure 35. As can be seen, the output power and overflow loss of the system basically remain unchanged, but with the increase of energy recovery, the loss power of the system decreases by $60 \%$.

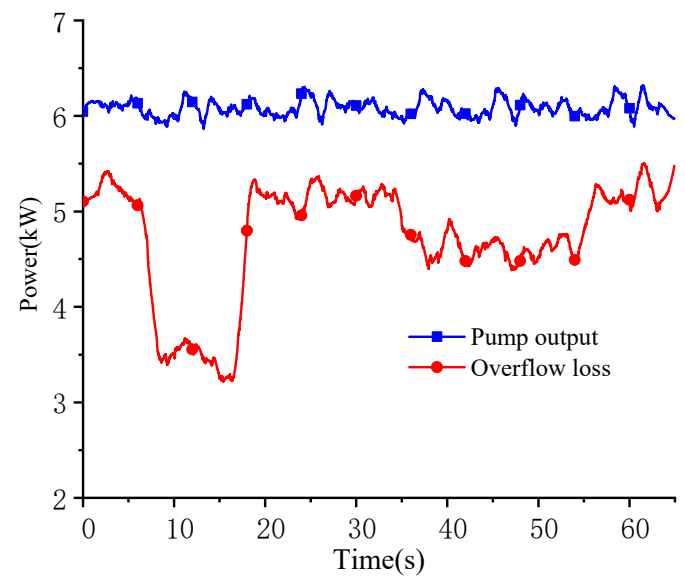

Figure 34. Power consumed in throttle-governing system without the energy regeneration system. 


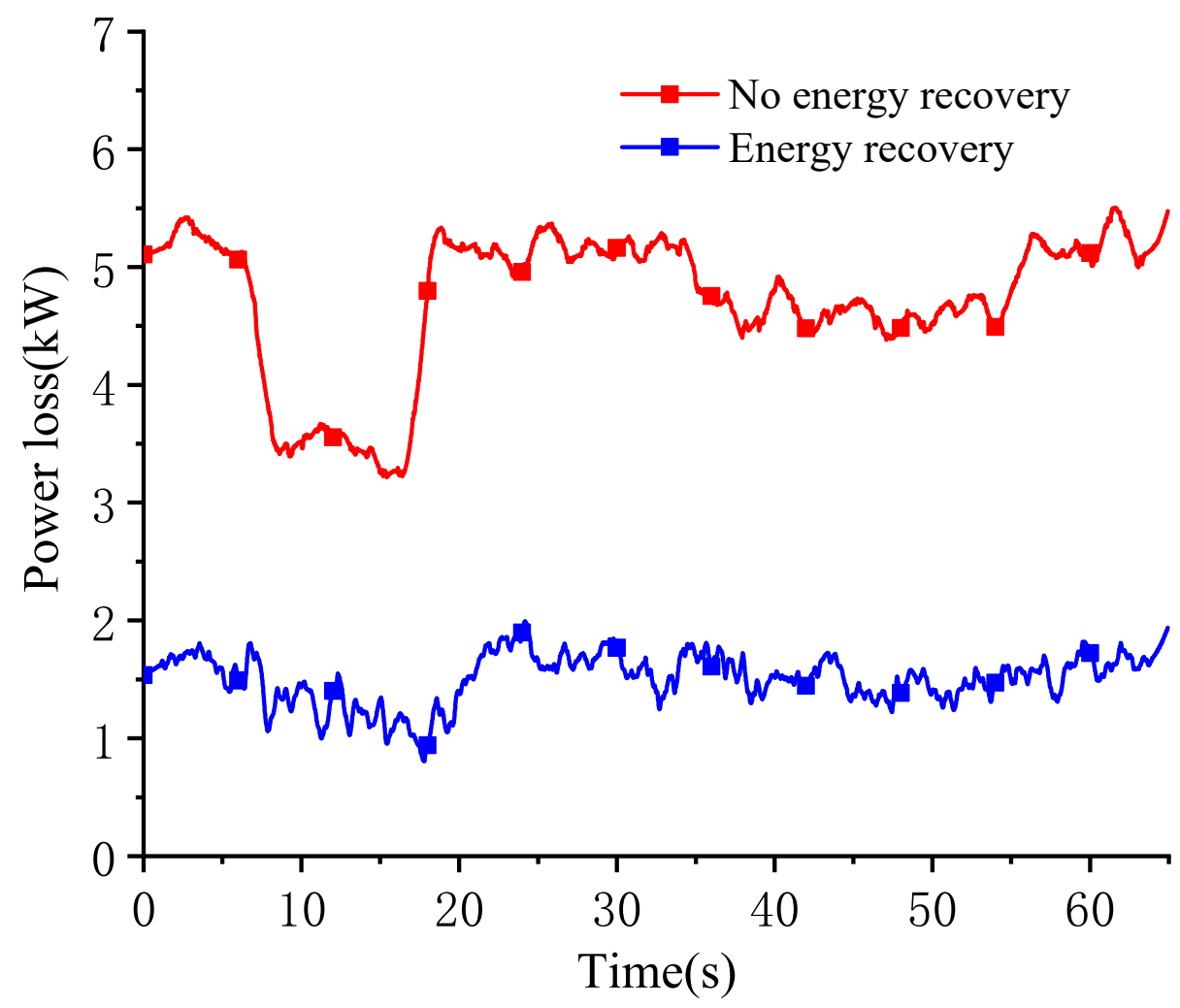

Figure 35. Power consumed in the throttle-governing system with the energy regeneration system.

\section{Conclusions}

In this paper, an overflow energy loss recovery system based on a hydraulic motorelectric generator is studied. Furthermore, a pressure difference control method of the relief valve based on pressure compensation is adopted. Through simulation analysis and experimental research, the effectiveness of the system is verified. The results show that the system has superior control characteristics. When the overflow pressure changes, the outlet pressure can respond quickly and achieve stability, and the system has strong antiinterference performance. After adding the energy recovery unit, the pressure regulating characteristics of the relief valve are improved, and the pressure regulating deviation of the relief valve is reduced from $10 \%$ to $2.8 \%$, and the pressure control accuracy of the relief valve is improved. By reducing the pressure difference of the relief valve, more overflow energy can be recovered.

Author Contributions: Z.L. proposed the idea of relief energy regeneration. T.L. developed the structure and working mode. L.S. wrote the paper. All authors have read and agreed to the published version of the manuscript.

Funding: The authors acknowledge the support of National Natural Science Foundation of China (51875218), Excellent Outstanding Youth Foundation of Fujian Province of China (2018J06014), Natural Science Foundation of Fujian Province of China (2019J01060).

Institutional Review Board Statement: Not applicable.

Informed Consent Statement: Not applicable.

Data Availability Statement: All data are available in the public domain.

Conflicts of Interest: The authors declare no conflict of interest. 


\section{Abbreviations}

$p_{1} \quad$ the inlet pressure of the relief valve

$p_{2} \quad$ the outlet pressure of the relief valve

$\Delta p_{T} \quad$ the pressure difference between inlet and outlet of main spool of traditional pilot proportional relief valve

$p_{x} \quad$ the pilot valve core front chamber pressure, namely the spring chamber pressure

$A_{1}$ the cross-sectional area of the main valve core. F0 is the preload of the return spring of the main valve core

$A_{0} \quad$ the cross-sectional area of the pilot valve core

$F_{E M} \quad$ the output force of the proportional electromagnet at a certain current

$F_{f y} \quad$ the hydraulic force at the pilot valve port

$F_{a y} \quad$ the Coulomb friction force on the pilot valve core

$m$ the sum of the mass of the pilot valve core and the mass of the push rod

$D_{y} \quad$ the damping coefficient related to viscous friction

$K_{s y} \quad$ the equivalent spring stiffness. y0 is the pre-compression of the spring

$y \quad$ the pilot valve core displacement

$\alpha_{D} \quad$ the flow coefficient

$d \quad$ the pilot valve core diameter

$\beta_{1} \quad$ the pilot valve seat half cone angle

$Q_{y} \quad$ the pilot valve port flow

$Q_{R} \quad$ the flow through the fixed damping hole

$V_{x} \quad$ the spring chamber volume

$E \quad$ the hydraulic oil effective volume elastic modulus

$V_{x} \quad$ the spring chamber volume

$d_{R} \quad$ the fixed damping diameter

$\rho \quad$ the hydraulic oil density

$M \quad$ the sum of the mass of the main valve core and one third of the return spring

$D_{x} \quad$ the damping coefficient related to viscous friction

$K_{s x} \quad$ the equivalent spring stiffness

$x_{0} \quad$ the preload reduction of the return spring

$x \quad$ the displacement of the main spool

$F_{f x} \quad$ the steady-state hydrodynamic force on the main valve core

$F_{f a x} \quad$ the Coulomb friction force on the main valve core

$D \quad$ the main valve core diameter

$\beta_{2} \quad$ the main valve seat half cone angle

$Q_{1} \quad$ the main valve core inlet flow

$Q_{2} \quad$ the main valve core outlet flow

$V_{1} \quad$ the main valve core front cavity volume

$A(x) \quad$ the main valve port flow area. $\mathrm{p} 2$ is the main valve core outlet pressure

$Q_{x} \quad$ the main spool outlet flow change

$M(s) \quad$ the total transfer function of the system

$P_{k} \quad$ the transfer function of the forward path

$\Delta \quad$ the characteristic expression of the flow graph

$M_{1}(s)$ the closed loop transfer function of traditional proportional relief valve control system

$D_{m} \quad$ the displacement of hydraulic motor. $\mathrm{w}$ is the rotary speed of the hydraulic motor

$\eta_{m} \quad$ the volume efficiency of the hydraulic motor

$w \quad$ the rotary speed of hydraulic motor

$W_{1} \quad$ the input energy of relief valve. W2 is the regenerated energy of battery

$p \quad$ the input pressure of the relief valve. $q$ is the input flow of the relief valve

$t \quad$ the energy regeneration time

$U \quad$ the voltage of the battery. I is the current of the battery

$p_{0} \quad$ the pre-set open pressure of the relief valve

$Q_{m} \quad$ the flow rate of the hydraulic motor

$Q_{r t} \quad$ the threshold value of flow rate for energy recovery of relief valve

\section{References}

1. Kagoshima, M.; Komiyama, M.; Nanjo, T. Development of new hybrid excavator. Kobelco Technol. Rev. 2007, 27, 39-42. 
2. Ge, L.; Quan, L.; Zhang, X.; Dong, Z.; Yang, J. Power Matching and Energy Efficiency Improvement of Hydraulic Excavator Driven with Speed and Displacement Variable Power Source. Chin. J. Mech. Eng. 2019, 32, 1-12. [CrossRef]

3. Mahato, A.C.; Ghoshal, S.K. Energy-saving strategies on power hydraulic system: An overview. Proc. Inst. Mech. Eng. Part I J. Syst. Control Eng. 2020, 235, 095965182093162. [CrossRef]

4. Lin, T.; Chen, Q.; Ren, H.; Miao, C.; Chen, Q.; Fu, S. Influence of the energy regeneration unit on pressure characteristics for a proportional relief valve. Proc. Inst. Mech. Eng. Part I J. Syst. Control Eng. 2017, 231, 095965181769247. [CrossRef]

5. Quan, Z.; Quan, L.; Zhang, J. Review of energy efficient direct pump controlled cylinder electro-hydraulic technology. Renew. Sustain. Energy Rev. 2014, 35, 336-346. [CrossRef]

6. Hippalgaonkar, R.; Ivantysynova, M. Fuel savings of a mini-excavator through a hydraulic hybrid displacement controlled system. In Proceedings of the International Conference on Fluid Power, Dresden, Germany, 26-28 March 2012.

7. Joshua, Z.; Monika, I. Hybrid displacement controlled multi-actuator hydraulic systems. In Proceedings of the 12th Scandinavian International Conference on Fluid Power, Tampere, Finland, 18-20 May 2011.

8. Xu, B.; Yang, J.; Yang, H. Comparison of energy-saving on the speed control of the VVVF hydraulic elevator with and without the pressure accumulator. Mechatronics 2005, 15, 1159-1174. [CrossRef]

9. Kilic, E.; Dolen, M.; Caliskan, H.; Koku, A.B.; Balkan, T. Pressure prediction on a variable-speed pump controlled hydraulic system using structured recurrent neural networks. Control Eng. Pract. 2014, 26, 51-71. [CrossRef]

10. Lin, T.; Chen, Q.; Ren, H.; Lv, R.; Miao, C.; Chen, Q. Computational fluid dynamics and experimental analysis of the influence of the energy recovery unit on the proportional relief valve. Proc. Inst. Mech. Eng. Part C J. Mech. Eng. Sci. 2017, 232, 697-705. [CrossRef]

11. Lin, T.; Chen, Q.; Ren, H.; Zhao, Y.; Miao, C.; Fu, S.; Chen, Q. Energy Regeneration Hydraulic System via a Relief Valve with Energy Regeneration Unit. Appl. Ences 2017, 7, 613. [CrossRef]

12. Zhang, Z.; Zhou, H.; Teng, B.; Xiao, W.; Li, X. Method and System for Feedback Control of Braking Energy in Pure Electric Vehicle. WO. Patent CN2011/079235, 22 November 2012.

13. Liang, X. On improving energy utilization in hydraulic booms. Acta Polytech. Scand. Mech. Eng. 2002, 56, 1025-1029.

14. Li, J.; Zhao, J.; Zhang, X. A Novel Energy Recovery System Integrating Flywheel and Flow Regeneration for a Hydraulic Excavator Boom System. Energies 2020, 13, 315. [CrossRef]

15. Wei, W.; Li, Q.; Xu, F.; Zhang, X.; Jin, J.; Jin, J.; Sun, F. Research on an Electromagnetic Actuator for Vibration Suppression and Energy Regeneration. Actuators 2020, 9, 42. [CrossRef]

16. Diego-Ayala, U.; Martinez-Gonzalez, P.; McGlashan, N.; Pullen, K.R. The mechanical hybrid vehicle: An investigation of a flywheel-based vehicular regenerative energy capture system. Drive Syst. Tech. 2011, 222, 2087-2101. [CrossRef]

17. Dutta, R.; Wang, F.; Bohlmann, B.F.; Stelson, K.A. Analysis of Short-Term Energy Storage for Mid-Size Hydrostatic Wind Turbine. J. Dyn. Syst. Meas. Control 2012, 136, 813-822.

18. Chen, Q.; Lin, T.; Ren, H.; Fu, S. Novel potential energy regeneration systems for hybrid hydraulic excavators. Math. Comput. Simul. (MATCOM) 2019, 163, 130-145. [CrossRef]

19. Lin, T.; Wang, Q.; Hu, B.; Gong, W. Research on the energy regeneration systems for hybrid hydraulic excavators. Autom. Constr. 2010, 19, 1016-1026. [CrossRef]

20. Lin, T.; Wang, Q. Hydraulic Accumulator-Motor-Generator Energy Regeneration System for a Hybrid Hydraulic Excavator. Chin. J. Mech. Eng. 2012, 25, 1121-1129. [CrossRef]

21. Wang, T.; Wang, Q. Coupling effects of a novel integrated electro-hydraulic energy conversion unit. Int. J. Appl. Electromagn. Mech. 2015, 47, 153-162. [CrossRef]

22. Wang, T.; Wang, Q. Design and analysis of compound potential energy regeneration system for hybrid hydraulic excavator. Proc. Inst. Mech. Eng. Part I J. Syst. Control. Eng. 2012, 226, 1323-1334. [CrossRef]

23. Jeng, S.L.; Roy, R.; Chieng, W.H. A Matrix Approach for Analyzing Signal Flow Graph. J. Inf. Sci. 2020, $11,1-17$. 